Emilio Bouza'

José María Aguado ${ }^{2}$

Luis Alcalá ${ }^{3}$

Benito Almirante ${ }^{4}$

Patricia Alonso-Fernández

Marcio Borges ${ }^{6}$

Javier $\mathrm{Cobo}^{7}$

Jordi Guardiola ${ }^{8}$

Juan Pablo Horcajada ${ }^{9}$

Emilio Maseda ${ }^{10}$

Josep Mensa"11

Nicolás Merchante ${ }^{12}$

Patricia Muñoz ${ }^{13}$

José Luis Pérez Sáenz ${ }^{14}$

Miquel Pujol ${ }^{15}$

Elena Reigadas ${ }^{16}$

Miguel Salavert ${ }^{17}$

José Barberán ${ }^{18}$

\section{Recommendations for the diagnosis and treatment of} Clostridioides difficile infection: An official clinical practice guideline of the Spanish Society of Chemotherapy (SEQ), Spanish Society of Internal Medicine (SEMI) and the working group of Postoperative Infection of the Spanish Society of Anesthesia and Reanimation (SEDAR)

${ }^{1}$ Departamento de Medicina, Universidad Complutense de Madrid. Emérito Asistencial, Servicio de Microbiología Clínica y E. Infecciosas. Hospital General Universitario Gregorio Marañón, Madrid. Instituto de investigación Gregorio Marañón. Centro de investigación biomédica en red en Enfermedades Respiratorias (CIBERES).

${ }^{2}$ Departamento de Medicina, Universidad Complutense de Madrid. Jefe de Servicio de E. Infecciosas. Hospital Doce de Octubre, Madrid.

${ }^{3}$ Servicio de Microbiología y E. Infecciosas. Hospital General Universitario Gregorio Marañón. Madrid.

${ }^{4}$ Servicio de Enfermedades Infecciosas. Hospital Universitario Val D'Hebron. Barcelona.

${ }^{5}$ Servicio de Geriatria. Hospital Clínico San Carlos, Madrid

${ }^{6}$ Servicio de Cuidados Intensivos. Hospital Son Llàtzer".

${ }^{7}$ Servicio de Enfermedades Infecciosas. Hospital Ramón y Cajal. Madrid

${ }^{8}$ Servicio de Aparato Digestivo. Hospital Universitario de Bellvitge e IDIBELL, Universidad de Barcelona. Hospitalet de Llobregat, Barcelona.

${ }^{9}$ Servicio de Enfermedades Infecciosas. Hospital del Mar. Barcelona

${ }^{10}$ Servicio de Anestesia y Reanimación. Hospital Universitario La Paz. Madrid

${ }^{11}$ Servicio de E. Infecciosas. Hospital Clinic i Provincial. Barcelona.

${ }^{12}$ Unidad Clinica de Enfermedades Infecciosas y Microbiologia, Instituto de Biomedicina de Sevilla (IBiS), Hospital Universitario de Valme, Sevilla.

${ }^{13}$ Departamento de Medicina, Universidad Complutense de Madrid. Jefe de Servicio de Microbiología y E. Infecciosas. Hospital General Universitario Gregorio Marañón, Instituto de investigación Gregorio Marañón. Centro de investigación biomédica en red en Enfermedades Respiratorias (CIBERES).

${ }^{14}$ Servicio de Microbiologia. Hospital Universitario Son Espases. Mallorca.

${ }^{15}$ Infectious Diseases Department. Hospital Universitari de Bellvitge, Institut Investigacions Biomèdiques de Bellvitge (IDIBELL), University of Barcelona, Barcelona, Spain. Spanish Network for Research in Infectious Diseases (REIPI RD16/0016/0005).

${ }^{16}$ Servicio de Microbiología y E. Infecciosas. Hospital General Universitario Gregorio Marañón. Instituto de investigación Gregorio Marañón. Centro de investigación biomédica en red en Enfermedades Respiratorias (CIBERES). Madrid

${ }^{17}$ Servicio de Enfermedades Infecciosas. Hospital La Fe. Valencia.

${ }^{18}$ Servicio de Enfermedades Infecciosas. Hospital Monteprícipe. Madrid.

Article history

Received: 2 January 2020; Acepted: 26 January 2020; Published: 20 February 2020

\section{ABSTRACT}

This document gathers the opinion of a multidisciplinary forum of experts on different aspects of the diagnosis and treatment of Clostridioides difficile infection (CDI) in Spain. It has been structured around a series of questions that the attendees considered relevant and in which a consensus opinion was reached. The main messages were as follows:

CDI should be suspected in patients older than 2 years of age in the presence of diarrhea, paralytic ileus and unexplai-

Correspondence:

Emilio Bouza MD, PhD

Instituto de Investigación Sanitaria Gregorio Marañón

Servicio de Microbiología Clínica y E. Infecciosas

C/ Dr. Esquerdo, 46 - 28007 Madrid, Spain

Phone: +34- 91- 58684 53/Fax: +34- 91- 5044906

E-mail: emilio.bouza@gmail.com ned leukocytosis, even in the absence of classical risk factors. With a few exceptions, a single stool sample is sufficient for diagnosis, which can be sent to the laboratory with or without transportation media for enteropathogenic bacteria. In the absence of diarrhoea, rectal swabs may be valid. The microbiology laboratory should include $C$. difficile among the pathogens routinely searched in patients with diarrhoea.

Laboratory tests in different order and sequence schemes include GDH detection, presence of toxins, molecular tests and toxigenic culture. Immediate determination of sensitivity to drugs such as vancomycin, metronidazole or fidaxomycin is not required. The evolution of toxin persistence is not a suitable test for follow up. Laboratory diagnosis of CDI should be rapid and results reported and interpreted to clinicians immediately.

In addition to the basic support of all diarrheic episodes, CDI treatment requires the suppression of antiperistaltic 
agents, proton pump inhibitors and antibiotics, where possible. Oral vancomycin and fidaxomycin are the antibacterials of choice in treatment, intravenous metronidazole being restricted for patients in whom the presence of the above drugs in the intestinal lumen cannot be assured. Fecal material transplantation is the treatment of choice for patients with multiple recurrences but uncertainties persist regarding its standardization and safety. Bezlotoxumab is a monoclonal antibody to $C$. difficile toxin $B$ that should be administered to patients at high risk of recurrence. Surgery is becoming less and less necessary and prevention with vaccines is under research. Probiotics have so far not been shown to be therapeutically or preventively effective. The therapeutic strategy should be based, rather than on the number of episodes, on the severity of the episodes and on their potential to recur. Some data point to the efficacy of oral vancomycin prophylaxis in patients who reccur CDI when systemic antibiotics are required again.

Key-words: Clostridiodes difficile, Clostridium difficile, Diarrhoea associated to C. difficile, Vancomycin, Metronidazole, Fidaxomicin, Fecal Material Transplantation (FMT), Bezlotoxumab, Vaccines, Probiotics, Monoclonal antibodies.

\section{Recomendaciones para el diagnóstico y tratamiento de la infección por Clostridioides difficile. Guía de práctica clínica de la Sociedad Española de Quimioterapia, Sociedad Española de Medicina Interna y grupo de trabajo de Infección Postoperatoria de la Sociedad Española de Anestesia y Reanimación}

\section{RESUMEN}

El presente documento recoge la opinión de un foro multidisciplinar de expertos sobre distintos aspectos del diangóstico y tratamiento de la infección por Clostridioides difficile (CDI) en España. Se ha estructurado alrededor de una serie de preguntas que los asistentes consideraron pertinentes y en las que se llegó a una opinón de consenso. Los principales mensajes fueron los siguientes:

CDI debe sospecharse en pacientes mayores de 2 años de edad ante la presencia de diarrea, ileo paralítico y leucocitosis inexplicada, aún en ausencia de los factores de riesgo clásicos. Salvo excepciones, es suficiente con una sola muestra de heces para su diagnóstico que pueden ser enviadas al laboratorio con o sin medio de transporte para bacterias enteropatógenas. En ausencia de diarrea, pueden ser válidos los isopados rectales. El laboratorio de microbiología debe incluir a $C$. difficile entre los patógenos buscados de rutina en pacientes con diarrea.

Las pruebas de laboratorio en diferentes esquemas de orden y secuencia incluyen la detección de GDH, la presencia de toxinas, las pruebas moleculares y el cultivo toxigénico. No se precisa la determinación inmediata de sensibilidad frente a fármacos como vancomicina, metronidazol o fidaxomicina. La evolución de la persistencia de toxina no es un test adecuado para el seguimiento del proceso.
El diagnóstico de laboratorio de CDI debe ser rápido y los resultados informados e interpretados a los clínicos con carácter inmediato.

Además del soporte básico de toda diarrea, el tratamiento de $C D I$ requiere la supresión de los agentes antiperistálticos, de los inhibidores de la bomba de protones y de los antibióticos, cuando sea posible. Vancomicina oral y fidaxomicina son los antibacterianos de elección en el tratamiento, restringiéndose metronidazol intravenoso para enfermos en los que no se pueda asegurar la presencia en la luz intestinal de los fármacos anteriores. El trasplante de materia fecal es el tratamiento de elección para pacientes con múltiples recurrencias pero persisten incertidumbres sobre su estandarización y seguridad. Bezlotoxumab es un anticuerpo monoclonal frente a la toxina $\mathrm{B}$ de $\mathrm{C}$. difficile que debe administrarse a pacientes con alto riesgo de recurrencias. La cirugia es un procedimiento cada vez menos necesario y la prevención mediante vacunas se encuentra en fase de investigación. Los probióticos no han demostrado, hasta el momento, eficacia terapéutica ni preventiva. La estrategia terapéutica debe basarse, más que en el número de episodios, en la gravedad de los mismos y en la potencialidad de recurrir. Algunos datos apuntan a la eficacia de la profilaxis con vancomicina oral en pacientes que recurren cuando vuelven a precisar antibióticos sistémicos.

Palabras clave: Clostridiodes difficile, Clostridium difficile, diarrea asociada a $C$. difficile, vancomicina, metronidazol, fidaxomicina, Trasplante de materia fecal, bezlotoxumab, vacunas, probióticos, anticuerpos monoclonales

\section{INTRODUCTION}

Clostridiodes difficile (CD) is the leading cause of infectious diarrhea in adults in contact with the health-care setting $[1,2]$, but also an increasing proportion of $C$. difficile infections (CDI) are either community-acquired or of community onset [3-7]. In Spain, the estimated incidence of CDI acquired in relationship with HealthCare Facilities is 6,5 episodes per 10,000 patientdays of admission and 22.3 episodes per 100.000 inhabitants [8], but many episodes remain undetected. The underdiagnosis was evaluated in three different Nationwide studies in Spain. The results across these studies showed a decrease in missed diagnoses from 76\% to 50\% between 2008 and 2013 [8-11]. The underdiagnosis, in Spain, is due to the lack of clinical suspicion or to the use of insensitive diagnostic tests. In the European EUCLID study, that followed the methodogy of the Spanish Studies, the mean number of CDI episodes was of 7 episodes of CDI per 10,000 patient-bed days and it was estimated that 23\% of the cases were missed [12]. Most cases described in Spain have mild or moderate severity, are health care-associated, and have a recurrence frequency ranging from $12 \%$ to $18 \%[6,11,13]$.

Recurrent CDI (rCDI) represents an incremental morbidity and cost for patients and institutions. It falls not just on the length-of stay, which has the highest weight, but also on re-hospitalisation, serious complications, laboratory tests and medications $[14,15]$. In addition to the economic burden, an important factor that needs to be taken into account in pa- 
tients suffering from $r C D I$ is the impact on the quality of life (QoL) of this disease $[16,17]$.

Accurate diagnosis of CDI is suboptimal and laboratory methods to diagnose the disease can be misleading due to the development in the last years of multiple tests with different sensitivities, specificities and targets (bacterium, toxins, cell membrane enzyme, toxin genes) $[8,10,18,19]$.

Finally, current recommendations for treatment vary according to the country issued and the clinical definition, and have been linked mainly to the number of episodes of the patient and the severity of CDI. However, treatment of patients with CDI recurrences and those with severe complicated forms is not so clear and is based on limited clinical evidence, and new treatments or strategies are needed $[2,20,21]$. Several recently completed prospective, randomized, double blind clinical trials have showed that fidaxomicin can be as effective as vancomycin in achieving clinical cure and superior in preventing recurrence $[22,23]$. New published evidence has demonstrated that patients receiving bezlotoxumab, a fully human monoclonal antibody especific against the toxin $B$ of $C D$, plus antibiotic treatment against CDI had a $40 \%$ of relative reduction of rCDI at 12 weeks [24].

However, the administration of antimicrobial agents to treat $\mathrm{rCDI}$ has been put into perspective with another therapeutic and preventive alternative: Fecal Material Transplantation (FMT) [25-27]. FMT is effective in reducing the incidence of multiple recurrences, however, the technique is cumbersome, not available in the majority of institutions and raises concerns related to the best way, the best dose and the potential transmission of currently unknown microorganisms [28-37]. Also, in the near future, there might be the possibility of prevention with vaccination $[38,39]$ or with antibiotics.

Aware of the problem of CDI, a panel of experts were convened to develop an opinion document with recommendations on the diagnosis and treatment of CDI, based on the best available evidence for achieving the greatest clinical efficacy adapted to the situation in Spain. The present document is structured in several questions, agreed among the participants, about controversial issues in the diagnosis and treatment of $C D$ in our country. Every answer has a review of the evidence supporting or refuting the issues raised. Finally, the recommendations based on this review are issued.

\section{QUESTION 1. When should CDI be suspected in pa- tients older than 2 years?}

Traditional risk factors for acquision of CDI are antimicrobial treatment within the previous 6-8 weeks, advanced age and prolonged hospital stay [6, 40-48]. However, recent studies have shown that a significant proportion of CDI episodes affect patients without any of these risk factors, thus outlining the need for a greater awareness of this disease. In
2008, a study performed in more than 100 Spanish hospitals showed that most patients unsuspected to have CDI did not have traditional risk factors for CDI such as advanced age or hospitalization [10]. A two-point prevalence study performed in Spain and other European countries in January and July 2013 showed similar results [8, 12]. CDI is also relatively common in nonhospitalized patients both with prior contact with the health care system or without [6]. When compared with patients with hospital-acquired CDI (HA-CDI), those with community-acquired CDI (CA-CDI) were younger, more likely to be female, had lower comorbidity scores, and were less likely to have severe infection or have been exposed to antibiotics [6, 49]. One North-American population-based study performed in the period 2004-2007 also showed a high incidence rate for CA-CDI and almost a third of these episodes were from patients that had not received antimicrobials in the six months prior to the diagnosis, and 17\% did not have any traditional risk factors for CDI [50]. Another study by Naggie et al, showed that $40 \%$ of the patients with CA-CDI had not received antimicrobials prior to diagnosis [51]. In a recent study published by Spanish authors, the use of rifaximin in cirrhotic patients was associated with breakthrough CDI [52]. This evidence supports that common risk factors for CDI may not be present in all patients, therefore each probable case has to be evaluated in an individualized manner and in the presence of a diarrheic episode all patients should be suspected of CDI until proven otherwise.

Some people become carriers of CD or develop a mild, selflimited diarrhea while others develop severe colitis and may have multiple relapses of the disease $[53,54]$. Patients with $C D$ intestinal disease usually have mild or severe diarrhea and abdominal pain, low-grade to high-grade fever, and leukocytosis; they may have hypovolemia, shock, and hypoalbuminemia. Some patients develop fulminant colitis associated with a colonic ileus, in which case the patient may not have diarrhea. Physicians rarely suspect $C D$ disease in the absence of diarrhea. A colonoscopy to look for pseudomembranes and to obtain a stool sample is not necessary to make or confirm the diagnosis in the majority of the episodes and may even be associated with adverse events. A computed tomography scan may be diagnostic of $C D$ colitis, provided physicians think of this disease in the absence of diarrhea. Patients with acute toxic megacolon may have abdominal pain, fever, leukocytosis [55], and hypoalbuminemia, but they may not have diarrhea. Many clinicians would suspect ischemic colitis, rather than CD colitis. This form of CD disease has a very high mortality rate and a poor response to vancomycin and metronidazole $[56,57]$.

One of the most uncertain points of CDI diagnosis is the clinical significance of the detection of a toxigenic $C D$ strain in a diarrheic patient aged less than 2 years. The low number of toxin receptors in the intestinal lumen in patients aged less than 2 years and the high frequency of viral pathogens producing diarrheic episodes indicate the doubtful role of $\mathrm{CD}$ in the diarrheical diasease in this age group. In a study performed in a Ma- 
drid hospital, all diarrheic stool samples received from children younger than 2 years old were screened for CD. Positive (cases) and negative (controls) children were compared and also cases receiving or not specific anti CDI treatment. No differences in clinical behaviour were detected and all the patients, including $C D$ cases, independently of the administration of metronidazole, were cured of the diarrheic episode [58]. A group of experts recently found a lack of evidence of an unmet need to treat CDI infections in infants under 2 years of age [59].

In conclusion, data in the literature supports that CDI should be suspected in diarrhoeic episodes in patients of any age except for those younger than 2 years even in patients with or without traditional risk factors for CDI. Some patients may not have diarrhea, such is the case of colonic ileus or "unexplained" leukocytosis, making the clinical diagnosis more difficult and sometimes resulting in fulminant colitis

QUESTION 2. Which is the optimal number of stool specimens that should be sent to the Microbiology laboratory for the diagnosis of CDI?

The positivity rate of subsequent specimens from patients with a first negative sample is very low and, therefore, testing a second specimen from a negative patient is more likely to be a false-positive [60-62].

International guidelines of three of the most important societies, the Infectious Diseases Society of America (IDSA), the Society for Healthcare Epidemiology of America (SHEA), and the American Society for Microbiology (ASM) recommend to test only one stool specimen per patient for the diagnosis of CDI $[20,63]$. The European Society of Clinical Microbiology and Infectious Diseases (ESCMID) does not recommend repeated sample submission during the same episode in a endemic situation although it may be useful in a epidemic situation [64].

In conclusion, data in the literature supports that the best cost-effective number of stool specimens needed for the diagnosis of CDI is one stool specimen and, only exceptionally, two or more stool samples.

QUESTION 3. Which transportation media can be used to send specimens to the laboratory for CDI diagnosis?

Although CD is an anaerobic pathogen, the ability of this microorganism to form spores allows the transportation of specimens for the diagnosis of CDI in aerobiated containers without any media to maintain viability of the microorganism [65-68]. Guidelines performed by IDSA and SHEA societies recommend transporting stool specimens in clean, watertight containers, without transport medium to diagnose CDI [63]. However, in a great number of laboratories, stool samples with a clinical request for aerobic enteropathogens like SalmoneIla spp., Shigella spp., or Campylobacter spp. are sent to the Microbiology laboratory preserved in transport media. One of the most common media used is Cary-Blair medium, that pre- vents overgrowth of most Enterobacteriaceae and is effective in the preservation for long periods of common enteropathogens. Additionally, this medium does not affect the performance of four different diagnostic methods used to diagnose CDI (glutamate dehydrogenase immnunoassay, toxins A and $B$ immunoassay, cell culture cytotoxicity assay and real-time PCR targeting the toxin B gene) [69-71] Samples transported in sporicidal medium like formaldehyde for parasites must be rejected. Samples must be sent as soon as possible to the microbiology laboratory. In general, it is recommended to preserve samples at $2-8^{\circ} \mathrm{C}$ the first $48-72$ hours or frozen at -60 to $-80^{\circ} \mathrm{C}$ if samples will not be processed within the following 72 hours [19].

In conclusion, data in the literature supports that both, samples without any transport medium and samples with transport medium for aerobic enteropathogens, such as Cary-Blair, are suitable for the diagnosis of CDI.

QUESTION 4. Should stool specimens without a $C$. difficile request be processed for $C$. difficile diagnosis?

As previously recommended, clinicians should suspect CDI in any patient suffering diarrhea with or without traditional risk factors for this disease, including outpatients. However, clinicians are not always aware of the presence of common or uncommon risk factors for this illness and, even if it is the case, clinicians sometimes do not remember to include the request for CDI diagnosis in samples sent to the Microbiology laboratory. Clinical misdiagnosis can occur even in patients with traditional risk factors like hospitalized patients. Even in the best scenario for CDI recognition, as is the case of nosocomial diarrhea, the clinical suspicion of CDI is far from optimal, where about $30 \%$ of nosocomial CDI episodes are missed due to a lack of processing specimens for $\mathrm{CDI}[9,55]$.

In conclusion, it seems clear that the microbiology laboratory has an important role in improving the diagnosis of CDI. Since the degree of suspicion of physicians may be insufficient, the microbiologist should consider, with the available information, to perform diagnostic techniques for $C$. difficile in samples of unformed faeces regardless of what was requested

QUESTION 5. Should specimens other than diarrheic stool specimens be processed for CDI?

There is a general consensus in all international guidelines that watery or loose stools are the only specimens that should be collected to diagnose CDI in diarrheic patients with suspicion of this disease, in day to day clinical practice $[63,64]$. However, CD can produce infections in which patients do not develop diarrhea, like ileus, toxic megacolon, pseudomembranous colitis without diarrhea or abdominal distension. In these cases, it may not be possible to obtain an unformed stool specimen for a CDI diagnosis. In these situations, diagnostic procedures recommended by international guidelines are not applicable. English guidelines performed by the Advisory Com- 
mittee on Antimicrobial Resistance and Healthcare Associated Infection (ARHAI) recommend using in these situations procedures such as colonoscopy, white cell count, serum creatinine or abdominal computerized tomography scanning [72]. On the other hand, guidelines performed by the SHEA and IDSA societies recommend rectal specimens obtained by means of cotton swabs for the etiologic diagnosis of CDI $[63,64]$. Guidelines from the ASM do not recommend rectal specimens in these situations and only suggest using formed stool specimens, when present, and after consensus with clinicians [73].

Culture of rectal specimens are as sensitive as stool culture for the diagnosis of CDI [74], and the sensitivity, specificity, positive predictive value, and negative predictive value of testing perirectal swabs versus stool specimens using PCR are similar [75]. The culture of colon biopsies obtained by colonoscopy has been an acceptable procedure for diagnosis of CDI for a long time, however, diagnosis based on stool specimens, which are less invasive and cheaper, could be a better option for CDI diagnosis [69]. To clarify this question, a comparison between diagnostic methods in both colon biopsies and stool specimens was evaluated in a retrospective study in Spain. The study showed that sensitivity of colon biopsies to diagnose CDI $(21.3 \%)$ was significantly lower than that obtained using simultaneous stool specimens (94.7\%) [76].

In conclusion, data from the literature shows that rectal specimens are useful for CDI diagnosis in patients in which stool specimens cannot be obtained. Furthermore, stool specimens are more sensitive than colonic biopsies for the diagnosis of CDI in patients with colitis.

\section{QUESTION 6. What combination of laboratory tests is most cost effective and therefore recommended for an} optimal diagnosis of CDI?

Currently, there is no diagnostic test for CDI that alone can be sufficiently cost-effective to be used in the rapid diagnosis of the disease. As a consequence, diagnostic algorithms have been designed to take advantage of the benefits of each diagnostic test [77-79]. Rapid detection of toxins A and/or B can be performed with enzyme immunoassays (EIAs). At first, laboratories used EIAs that detected only toxin A but, with the dissemination and higher frequency of strains toxin A-/toxin $\mathrm{B}+$ producing $\mathrm{CDI}$, these were replaced by EIAs capable of detecting both toxins [80-83]. Some comparative studies have shown that ElAs have sensitivity values of 40-60\% when compared with toxigenic cultures [84-90]. On the other hand, the specificity of most of these tests is higher than $90 \%$. The American Society for Microbiology, ASM, considers these tests as techniques with low sensitivity and strongly recommends that these tests are not used as stand-alone tests [73]. In Europe, an analysis performed by the ESCMID committee concerning 13 commercial ElAs that detect toxins A and/or B also showed the deficiency of sensitivity of these tests and concluded that CDI diagnosis should be performed with more sensitive tests [64].

Detection of the enzyme glutamate dehydrogenase $(G D H)$, a protein produced in large quantity by most of the $C D$ strains (toxigenic and non-toxigenic), is another rapid test that allows the detection of $\mathrm{CD}$. The sensitivity of this test is higher than toxin detection alone, between 85\%-95\%, however the specificity and positive predictive value are relatively low since it can detect strains that produce toxins as well as nonproducing strains $[91,92]$. Due to the relative low specificity of tests based in GDH detection alone, main societies do not recommend the latter as single tests for rapid diagnosis of CDI [63]. Currently, there are commercialized diagnostic tests that include detection of both GDH antigen and toxins $\mathrm{A}$ and/or $\mathrm{B}$, with the main advantage of offering results simultaneously.

In recent years, the CDI diagnostic conundrum has been dramatically transformed by the development of commercial nucleic acid amplification tests (NAATs). NAATs are molecular assays that mostly utilize real-time PCR or loop-mediated isothermal amplification to directly detect the $t c d A$ or $t c d B$ genes encoding toxin $A$ or $B$, respectively, from stool specimens [93-103]. Due to the rapid uptake of NAATs there are now a great number of commercial products in the market, most of them FDA approved, like the BD MAX system (Becton Dickinson), Xpert ${ }^{\circledR}$ C. difficile (Cepheid), Prodesse ${ }^{\circledR}$ ProGastroTM CD (Gen-Probe) and Illumigene ${ }^{\circledR}$ C. difficile (Meridian), with an average of turnaround time between $45 \mathrm{~min}-3$ hours. The majority target the $\operatorname{tcd} B$ gene, and some can detect one or both genes of the binary toxin, even hipervirulent ribotype 027 strains that have mutations or deletions of the repressor gene $\operatorname{tcd} C[104,105]$. Sensitivity values of most of these techniques are very high with values greater than $90 \%$ and specificities greater than 98\% when compared with toxigenic culture, however, the positive predictive value of NAATs for CDI can be low to moderate (80\%-95\%), depending upon disease prevalence and the limit of detection of the assay [21]. The other problem of NAATs is their high cost when used as stand-alone tests. This limitation precludes them as a systematic alternative for diagnosis of CDI in most laboratories [104].

The cytotoxin assay has been traditionally considered the gold standard for CDI diagnosis. This technique uses tissue cultures to detect CD toxins from diluted stool specimens. This assay is highly specific because it uses specific antibodies for neutralization. However, numerous studies have shown that the cytotoxin neutralization assay is only 65 to $80 \%$ sensitive to detect toxigenic $C D$ isolates in comparison to toxigenic culture, which is performed by isolating CD on selective media and demonstrating cytotoxin production by the cultured organism [106-108]. A rising group of experts considers that a negative cytotoxin assay with a positive toxigenic culture indicates a low concentration of free toxin in the stools, not able to be detected by the cytotoxic assay alone [79, 109]. For this reason, the ASM recommends using toxigenic culture or NAATs as a confirmatory test of the rapid algorithms [21].

Due to the limitations of each of the individual tests for a rapid and correct diagnose of CDI, several multi-step algorithms have been proposed (figures 1 and 2). These algorithms have as screening test the detection of GDH by EIA due to its high sensitivity to detect CDI [110-113]. As most specimens are negative, the GDH screening step substantially reduces the 
number of specimens that require evaluation with more specific methods. Since both toxigenic and nontoxigenic CD strains express GDH, a positive GDH ElA requires confirmation with a sensitive assay for detection of toxin A or B or their genes. Overall performance including turnaround time of a GDH-based algorithm depends on the secondary tests used to follow up a positive GDH result. GDH detection followed by a NAAT is considered a two-step algorithm and has approximately a 90\% sensitivity, and specificity higher than 99\% [19]. A three-step algorithm detects toxins $\mathrm{A}$ and/or B between the GDH detection and NAATs, reducing almost by $50 \%$ the number of molecular tests needed [19]. However, in the recent update of CDI guidelines published recently by IDSA and SHEA the recommendation is to use a stool toxin test as part of a multistep algorithm (i.e., GDH plus toxin; GDH plus toxin arbitrated by NAATs; or NAATs plus toxin) [21]. These procedures have been evaluated by several authors and have a sensitivity of $85-90 \%$ and specificity greater than $99 \%[77,85,95,114-117]$.

Another traditional and less costly method for the diagnosis of CDI is the toxigenic culture; it has increased sensitivity over cytotoxicity and it is based on the detection of toxin production in the microorganism after isolation in culture. A downside to this technique would be the 48 hours to obtain bacterial growth. Published literature shows a controversy in the diagnosis of $\mathrm{CDI}$ in patients in which the results of the cytotoxic assays differ from the toxigenic culture. In a study by Reigadas et al, the authors observed that CDI episodes positive by cytotoxicity assay were more severe than those positive only by toxigenic culture. However, in their study, there were a significant proportion of CDI cases (31.9\%) that would have been missed if only cytotoxicity had been considered, including 10\% of severe CDI cases and one patient with pseudomembranous colitis. Additionally, in the same study, $45 \%$ of the CDI cases had a negative toxin portion $E I A$, which exemplifies the need for further testing samples with a positive GDH portion and a negative toxin EIA portion test, by PCR or toxigenic culture [118].

Some situations call for a change in the diagnostic algorithm. This is the case of $\mathrm{CDI}$ due to ribotype 027 strains that are usually more severe, with a higher transmission and recurrence rate than CDI caused by other ribotypes. In case of suspicion of an outbreak due to this ribotype, it is recommended to perform a rapid molecular test that specifically detects this ribotype $[19,119]$.

In conclusion, data reported in the literature shows that detection of GDH by EIA as a screening test followed by a rapid confirmatory technique as a NAAT alone or together with the detection of toxins by EIA is the most cost-effective procedure for the rapid diagnosis of CDI (figure 1 and 2). Toxigenic culture is a slow but sensitive and low-cost method for detecting CDI in patients with negative EIA or cytotoxicity.

QUESTION 7. When and how to perform antimicrobial susceptibility tests to $C$. difficile isolates?

For a long time, the susceptibility testing of the traditional antimicrobials metronidazole and vancomycin was not even recommended because the universal activity of these drugs was not questioned. However, different in vitro susceptibility studies performed during the last years have showed the existence of toxigenic isolates of $\mathrm{CD}$ resistant to these drugs.

In 1997, Barbut and colleagues found one resistant strain showing an MIC to metronidazole of $16 \mathrm{mg} / \mathrm{L}$ by the agar dilution method [120]. During the period 1993-2000, Peláez and colleagues [121] detected 26 isolates resistant to metronidazole from 415 isolates tested (6.3\% of resistance, MICs: $\geq 32 \mathrm{mg} / \mathrm{L}$, agar dilution method) in Spain. A posterior analysis performed

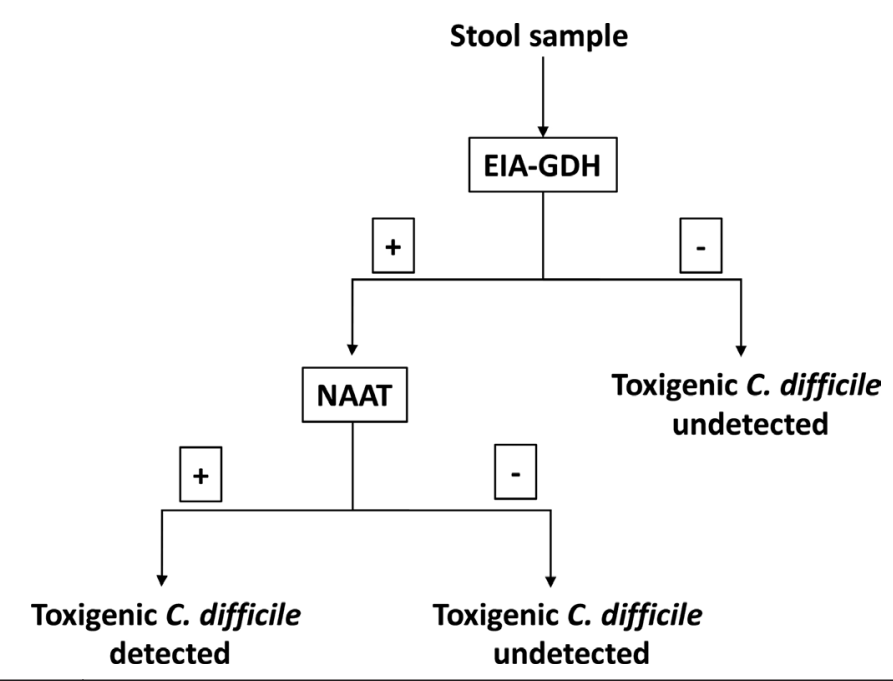

\begin{tabular}{l|l} 
Figure 1 & A rapid, cost-effective algorithm for the diagnoses CDI (two \\
steps)
\end{tabular} steps)

EIA-GDH: Detection of glutamate dehydrogenase by enzyme immunoassay

NAAT: nucleic acid amplification test 


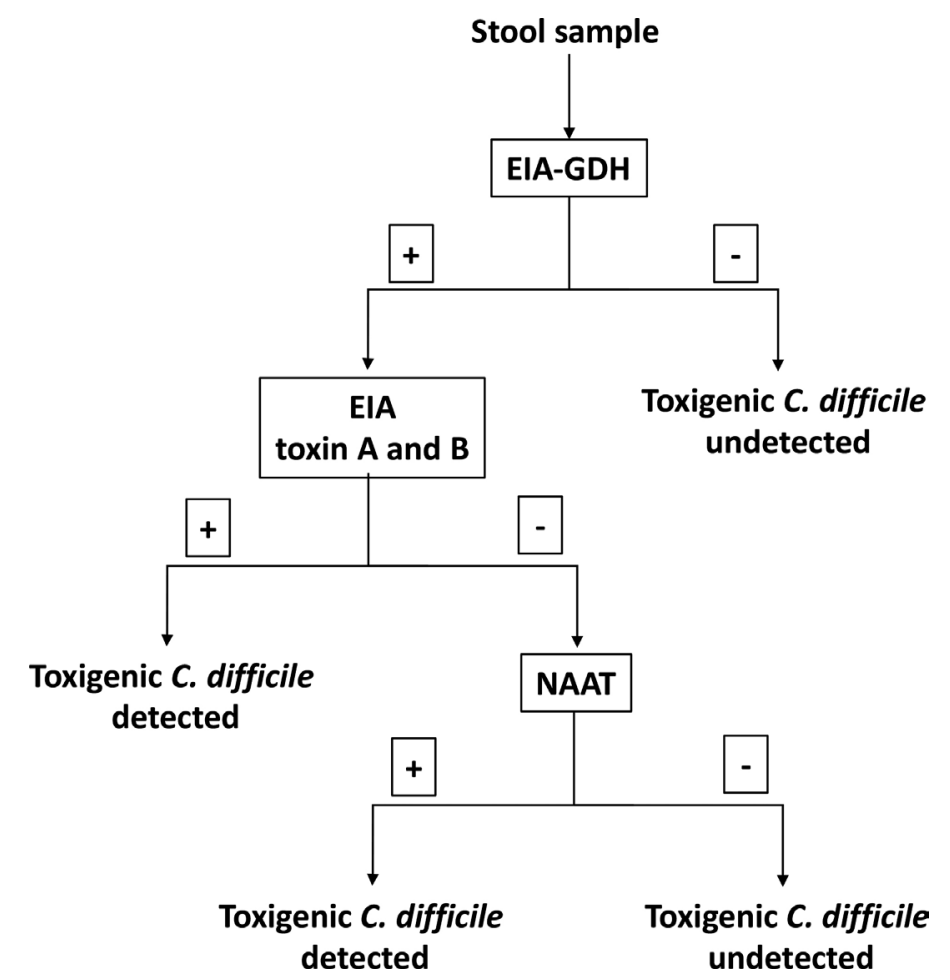

Figure 2 A rapid, cost-effective algorithm for the diagnoses CDI (three steps)

EIA-GDH: Detection of glutamate dehydrogenase by enzyme immunoassay

ElA toxin A and B: Detection of toxin A and B by enzyme immunoassay

NAAT: nucleic acid amplification test

by Peláez et al. showed that resistance to metronidazole was heterogeneous and that it can be lost in strains after prolonged periods of storage due to freezing and thawing [122]. In an Israelite study performed, authors described a $2 \%$ of resistance to metronidazole (1/49 isolates, MIC: $\geq 32 \mathrm{mg} / \mathrm{L}$, E-test method) [123]. A similar resistance rate was found in toxigenic strains isolated during 2004 to 2006 in Ontario, Canada (19/1,080 isolates, MICs: $\geq 32 \mathrm{mg} / \mathrm{L}$, E-test method) [124]. Recently, Huang and colleagues reported a $23.1 \%$ of resistance to metronidazole in primary fresh toxigenic $C$. difficile strains isolated from 2008 to 2009 in China (18/78 isolates, MICs $\geq 32 \mathrm{mg} / \mathrm{L}$, E-test method) [125]. As occurred in the Spanish study, the Canadian and Chinese isolates had such an heterogeneous resistance that most of the resistant isolates turned into sensitive to metronidazole after serial passages $[122,124]$. Although not as frequent, isolates of $\mathrm{CD}$ with intermediate resistance to vancomycin (MIC>2 mg/L) have been reported [126-129]. On the other hand, fidaxomicin has shown a good activity against CD with most isolates having MICs lower than $1 \mathrm{mg} / \mathrm{L}$ being the highest MIC ever reported, to our knowledge, of $2 \mathrm{mg} / \mathrm{L}$ [130-137].

Concentration in colonic mucosa of metronidazole and its metabolite hydroxymetronidazole is considered bactericidal in patients with acute disease receiving oral or intravenous metronidazole, but as the diarrhea improves neither substance is detectable in the faeces of diarrhea caused by CD (mean con- centration of $9.3 \mu \mathrm{g} / \mathrm{g}$ in watery stools and of $1.2 \mu \mathrm{g} / \mathrm{g}$ in formed stools) $[138,139]$

This finding has led to the EUCAST committee to decrease the metronidazole breakpoint from $16 \mathrm{mg} / \mathrm{L}$ to $4 \mathrm{mg} / \mathrm{L}$ [140]. Conversely, fecal levels of vancomycin and fidaxomicin in the colon lumen are greater than metronidazole with concentrations of $64-760 \mu \mathrm{g} / \mathrm{g}$ on day 2 and $152-880 \mu \mathrm{g} / \mathrm{g}$ on day 3 post-treatment for vancomycin and as high as 3,000 mg/L for fidaxomicin [120].

Although Clinical and Laboratory Standards Institute [126] guidelines do not recommend routine susceptibility testing for CD isolates, because correlation of MICs with clinical failures has not been established, they advocate in performing an annual surveillance testing to detect emerging resistance. The surveillance should be done by the hospital laboratory if expertise is available or, if not, by a reference laboratory. If possible, the guidelines recommend to test isolates collected over several months and stored until a total of 50-100 strains are available for later batch testing using preferably an agar dilution method [126].

In conclusion, data in the literature suggests that sensitivity testing should be performed annually to detect the emergence of resistance or in specific situations and in reference laboratories, but not on a routine daily basis 


\section{QUESTION 8. Is it necessary to follow-up patients with CDI with laboratory tests?}

Generally, in non-complicated CDI cases, the therapeutic response for $C D I$ involves the resolution of fever (if present) on the first day and of diarrhea before the fourth or fifth day [131]. This clinical resolution of the disease may not be accompanied by a microbiological clearance of CD toxins, as CD can survive in the lumen of cured patients during several weeks or months $[132,133]$. In a study performed in healthy patients with previous recurrent $\mathrm{CDI}$, authors found that persistence of spores of $C D$ by the end of antibiotic therapy occurred in $56 \%$ of patients receiving metronidazole and $43 \%$ receiving vancomycin [134]. A similar observational study showed that nearly $20 \%$ of patients successfully treated for CDI had detectable spores in stool specimens at the time of the resolution of the diarrhea and it increased to 56\% one to four weeks later [141]. The lack of correlation demonstrated in these studies between clearance of colonic $C D$ and resolution of $C D I$ has led to international guidelines to recommend not to use culture or toxin detection to follow-up the evolution of patients with CDI $[20,52]$. In order to reduce false positives, some experts suggest that microbiological laboratories reject stool samples from patients treated for CDI with a microbiological diagnosis in the previous seven days [19], as well as from asymptomatic patients (unless suspicion of ileum or toxic megacolon) [21].

In conclusion, data in the literature shows that detection of toxigenic $C$. difficile from stool specimens is not a good method to follow-up the evolution of patients with CDI and should not be performed routinely.

QUESTION 9. When and how to report clinicians the results of laboratory tests for CDI?

Early recognition of an episode of $\mathrm{CDI}$ is a critical step to optimize the treatment of $C D$ and to control the transmission to other patients, and must be based in three mainstays: a correct suspicion of the illness by clinicians, an accurate and rapid laboratory diagnosis of $\mathrm{CDI}$, and a rapid and effective transmission of information of these results to the attending physician, infection prevention officer, and nursing staff $[20,52]$. The Centers for Disease Control and Prevention (CDC) recommends to work with microbiology laboratories to ensure rapid reporting of test results for CDI, including weekends and holidays, and to ensure that there is a process for providing results to the patient care area so that isolation precautions can be initiated promptly (Center for Diseases Control and Prevention, Guidelines for preventing transmission of MDROs, 2006) [135]. Due to the fact that $\mathrm{CD}$ is able to produce spores that persist in the environment for many months and are resistant to cleaning and disinfectant measures, this pathogen is highly transmissible $[132,133]$. Transmission of CD to the patient via transient hand carriage on healthcare workers' hands is thought to be the most likely common way of transmission [136]. Some prominent authors and scientific societies such as the SHEA, the Association for Professionals in Infection Control and Epidemiology, the CDC, the Healthcare Infection Control Practices Advisory Committee, and the Infectious Diseases Society of America [137, 138, 142-146] recommend several points to the health care facilities referring to the quarantine of $\mathrm{CDI}$ patients, use of antiseptic procedures such as the utilization of disposable gloves, mask and gown and hand-washing with soap and water, cleaning of patient-care equipment (such as thermometers, stethoscopes, etc.) before it is used with another patient, to enhance environmental cleaning with diluted bleach from all patient contact surface areas, to restrict the use of antimicrobials implicated as risk factors for $\mathrm{CDI}$, to provide an easy laboratory access for prompt and active surveillance toxin $B$ detecting at the earliest indication of a case of $\mathrm{CDI}$ and to use rapid and accurate tests to diagnose CDI in the laboratory.

Another important issue is that rapid and accurate laboratory recognition of a $\mathrm{CDI}$ episode is a key step to optimize the treatment of patients with CDI. Rapid report of a positive result can facilitate a prompt treatment that avoids the risk that an initial mild CDI episode may progress to severe colitis and toxic megacolon [147]. Delayed diagnosis can increase the time of patient exposition to inappropriate drugs as antiperistaltic or narcotics that can complicate CDI [148]. Similarly, fast information of a negative result favors the withdrawal of antimicrobials in patients with empiric treatment for CDI [52].

In conclusion, data from the literature suggests that rapid laboratory recognition of $\mathrm{CDI}$ is crucial for the control and management of this illness. Preliminary phone information of results obtained from the rapid diagnostic tests to the appropriate health care workers is recommended. Ideally, this information should be accompanied by test interpretation and treatment advice

\section{THERAPEUTIC OPTIONS FOR CDI}

QUESTION 10. What is the basic support approach for the treatment of patients with CDI?

The basic support approach for the treatment of patients with $C D I$ include: 1) a standard supportive care for patients who are hemodynamically unstable, consisting of rapid fluids and electrolyte intravenous replacement. 2) avoidance of the following precipitating factors: a) agents such as narcotics and loperamide that inhibit intestinal peristalsis, retain intestinal toxins, and increase the risk of toxic megacolon [149-151]; b) concomitant broad-spectrum antibiotics for other concurrent infections [an early switch to reduced-spectrum antibiotics should be performed if complete suspension of the treatment is not possible)]; and c) anti-ulcer medication, especially proton pump inhibitors (PPI) $[152,153]$.

In conclusion, the basic support approach for patients with CDI includes: fluids and electrolyte replacement, and removal of intestinal peristalsis inhibitors, anti-ulcer medication, and concomitant antibiotics, when feasible.

QUESTION 11. What are the antibiotics of choice for CDI treatment? 
The choice of initial antibiotic therapy for CDI depends on the severity of disease, the possibility of oral therapy, and the potential risk for recurrence. Initially, the first prospective, randomized studies in which patients were not stratified by disease severity demonstrated that both oral metronidazole and oral vancomycin were equally effective, over $90 \%$, in the first episode and first recurrence $[127,128]$. However, when patients were stratified based on the severity of the infection, vancomycin had a clinical response significantly better than metronidazole in severely ill subjects $(97 \%$ versus $76 \%, P=$ 0.02 [ [130]. More recent studies have demonstrated that vancomycin provides superior cure rates compared with metronidazole, with reduced side effects, even in mild cases $[154,155]$.

The European Society of Clinical Microbiology and Infectious Diseases (ESCMID) Guidelines in 2014 recommended metronidazole as first-line treatment for non-severe CDI and vancomycin as the first choice for severe CDI [20]. Nevertheless, results from a meta-analysis of large multicenter randomized controlled trials (RCT) showed that metronidazole is inferior to vancomycin in the treatment of CDI (non-severe and severe combined, with severe CDI defined as a white blood cell count $\geq 10,000 / \mathrm{mm} 3$, ten or more bowel movements per day, and severe abdominal pain)[154].

Fidaxomicin is a macrocyclic antibiotic approved in the USA and in Europe for the treatment of CDI [156]. Two completed prospective, randomized, double-blind, clinical trials showed that the rates of clinical cure after treatment with oral fidaxomicin (200 mg twice daily for 10 days) were noninferior to those after treatment with oral vancomycin (125 mg four times daily for 10 days); at the same time, a significant reduction in the rates of recurrence with an increase in the rate of sustained responses was also observed $[22,23]$. Oral fidaxomicin is well tolerated, with a safety profile comparable to that of oral vancomycin. There are no differences in the incidence of death or serious adverse events between the two drugs. A downside is that the cost of fidaxomicin is much higher $[23,157]$. However, in a recent Spanish stu$d y$, using a cost-utility analysis model, it has been observed that fidaxomicin is more cost-effective than vancomycin for treatment of $\mathrm{CDI}$ in patients with cancer, renal impairment, and/or with concomitant antibiotic treatment [158]. Subsequently, two other studies in patients with cancer or concomitant antibiotic treatment have demonstrated a significant superiority of fidaxomicin over vancomycin $[157,159]$.

Since the publication of the ESCMID guidance document in which fidaxomicin was reserved for patients with relapsing $\mathrm{CDI}$, a published meta-analysis and indirect treatment comparison suggested that fidaxomicin may be considered as firstline therapy for CDI in patients with a high risk of recurrence $[160,161]$. In this regard, recently published IDSA guidelines recommend vancomycin or fidaxomicin for best treatment of initial CDI. The dosage recommended is: vancomycin $125 \mathrm{mg}$ orally 4 times per day or fidaxomicin $200 \mathrm{mg}$ twice daily for 10 days (strong recommendation, high quality of evidence][21].

Severe CDI cases may be treated with either oral van- comycin or fidaxomicin. A recent prospective, multicenter study demonstrated that courses with either antibiotic resulted in similar treatment outcomes for patients afflicted with severe CDI $[21,162]$. When oral treatment is not possible, intravenous metronidazole should be used.

In conclusion, oral vancomycin is the recommended drug for an initial CDI episode; oral fidaxomicin should be considered in initial CDI episodes with a high risk of recurrence. In view of the evidence described above, the opinion of this group of experts is that the use of metronidazole should be restricted to situations in which vancomycin or fidaxomicin are contraindicated or an oral administration is not possible. Combination therapy (i.e. vancomycin and metronidazole) is not recommended in patients with severe CDI, with the exception of severe cases complicated with ileus

QUESTION 12. What additional antibiotics are being studied for the treatment of CDI?

Additional antibiotic options to the ones cited above exist, such as rifaximin [163-165], nitazoxanide [166-168], fusidic acid [169], tigecycline $[170,171]$, and teicoplanin $[128,172]$; however, we do not recommended any of those for routine $\mathrm{CDI}$ treatment. Their use in the treatment of recurrences might be overshadowed by the efficacy of the currently available strategies described above. Moreover, there are reports of resistance development to rifaximin $[52,173]$ and fusidic acid [169], which further discounts the use of these antibiotics as treatment options for CDI in any episode.

Novel antibiotics include cadazolid, a new oxazolidinone. Cadazolid is an inhibitor of CD protein synthesis, causing more suppression of toxin production and spore formation than vancomycin and metronidazole. In pre-clinical studies, cadazolid showed a potent bactericidal in vitro activity against CD (MIC90 of $0.25 \mathrm{mg} / \mathrm{L}$ ) and a low propensity for resistance development [174-176]. The results for the IMPACT I and IMPACT II phase 3, randomized clinical trials were recently published [177]. While safe and well tolerated, cadazolid failed to achieve the primary end-point of non-inferiority vs. vancomycin for clinical cure [177]. As a result, to the best of our knowledge, efforts to commercialize cadazolid for CDI have been halted.

Ridinilazole is another novel antibiotic currently undergoing clinical trials for the treatment of CDI. The precise mechanism of action of this antibiotic is not clear, however, it appears to impair cell division [178]. With limited activity against Gram-positive and Gram-negative intestinal aneaerobes and a low MIC (MIC90 of $0.125 \mathrm{mg} / \mathrm{L}$ ) for $\mathrm{CD}$, ridinilazole appears to be a promising candidate for treating CDI. A phase 2, randomized clinical trial comparing ridinilazole with vancomycin for the treatment of CDI demonstrated non-inferiority and a statistically significant superitory at the 10\% level. Moreover, the antibiotic was well tolerated with an adverse profile similar to that of vancomycin [179]. Phase 3 clinical trials comparing ridinilazole and vancomycin are ongoing [180]. 
In conclusion, data from the literature suggests that rifaximin, nitazoxamide, fusidic acid, tygecicline, and teicoplanin are currently not considered as therapy options for CDI, especially since new treatments and strategies for $r C D I$ reduce the risk of recurrence. Cadazolid has failed to achieve the primary end-point of non-inferiority vs. vancomycin for clinical cure in a recent published clinical trial. Ridinilazole is a promising antibiotic with phase 3 clinical trials recruiting patients at present to demonstrate non-inferiority over vancomycin for the treatment of CDI.

QUESTION 13. What are the contributions of bezlotoxumab to the treatment of CDI?

Bezlotoxumab is a recombinant human $\lg \mathrm{G} 1 / \mathrm{kappa}$ isotype monoclonal antibody approved globally in 2017 for use as an adjunctive treatment in patients at risk for rCDI [181]. Bezlotoxumab binds to regions of the combined repetitive oligopeptide domains of toxin B that partially overlap with putative receptor binding pockets. This monoclonal antibody blocks the action of $C$. difficile toxin $B$ and potentially averts the damage and inflammation that can lead to the symptoms associated with CDI [182].

In two global, phase III trials (MODIFY I and MODIFY II), bezlotoxumab demonstrated significant reductions in CDI recurrence compared with placebo (17\% vs $28 \%$ in MODIFY I and $16 \%$ vs $26 \%$ in MODIFY $I I ; P<.001)$ in adults receiving antibiotic treatment for primary CDI or rCDI [183]. In a secondary analysis, bezlotoxumab demonstrated better efficacy results in reducing $C D I$ recurrence in a group of patients at high risk for $C D I$ recurrence (patients with previous $C D I$ episodes, severe $\mathrm{CDI}$, older age ( $\geq 65$ years old), and infection with hypervirulent strains]. Bezlotoxumab also reduced rCDI, FMT, and CDI-associated 30 day re-admissions in participants with risk factors for rCDI. As a result, the Spanish therapeutic positioning report (IPT) [184] recommends the use of bezlotoxumab as adjuvant therapy for CDI treatment in patients at high risk of recurrence, including patients $\geq 65$ years old with a previous CDI episode in the last six months, immunosuppressed patients, patients with CDI caused by hypervirulent strains (such as 027 and 244), patients with severe CDI (Zar $\geq 2)$, and patients that exhibit a high probability of recurrence as evaluated by externally validated predictor models.

In conclusion, the monoclonal antibody bezlotoxumab is the first approved treatment for the prevention of $\mathrm{CDI}$ recurrence. It has demonstrated a $40 \%$ reduction of $\mathrm{CDI}$ recurrence when compared to placebo. Its efficacy is higher in sub-groups of patients at greater risk for recurrence

QUESTION 14. How should bezlotoxumab be used in clinical practice at present?

The efficacy of bezlotoxumab has already been discussed above. A single injection significantly decreases the inciden- ce of recurrences and that difference has been maintained in subgroups of special populations such as immunosuppressed, transplanted, elderly patients, patients in renal failure and other subgroups. The patients to be selected are obviously those in whom a high risk of recurrence is predictable. In this sense, the best-known elements of risk associated to the host are advanced age ( $\geq 65$ years), the need to maintain antibiotic treatment for baseline infection, deficiencies in humoral immunity response, serious underlying diseases and the need to continue taking proton pump inhibitors, among others [185]. As the microorganism is concern, it seems clear that strains with high toxin production, as is the case with many of those grouped as 027, are associated with an increased risk of recurrence [186-189]. Despite all these data, risk scores for predicting recurrences, based on the association of clinical signs or symptoms, have not functioned adequately on most studies [190-196] and only in some works are they attributed a certain orientative value $[197,198]$. Some authors have used also toxin production, through what we might consider a surrogate marker, that would be the amplification cycle of PCR curves. Early amplifications before cycle 24 would be associated with worse evolution and very late cycles (amplification cycles beyond 28) would be associated with colonization [6, 199-203].

Interestingly, these scoring systems show us that certain patients in the first episode of CDI have a higher risk of recurrence than other patients in the second episode [185].

Data derived from the Modify I and II studies analyzed by Gerding et al [185] suggest that $75.6 \%$ of hospitalized patients meet one or more risk factors for recurrence who would, therefore, be natural candidates to receive bezlotoxumab. In this study, the risks of recurrence are proportional to the risk factors of each patient. With one risk factor the recurrence rate was $31 \%$ but with 3 or more risk factors, recurrences reached $46 \%$. In this most-at-risk population, the reduction in recurrent episodes after receiving bezlotoxumab was 53\%. However, not all risk factors are equally predictive $[193,194,198,204]$ and none of these models or scores seem to have been widely accepted.

Unfortunately, the latest clinical practice guidelines issued recently by the Infectious Disease Society of America (IDSA), although they include 53 therapeutic recommendations, do not provide recommendations or guidance on the use of bezlotoxumab in clinical practice [21].

This working group, thinking of the need for a progressive introduction of this drug in the medical practice of our country and considering economic factors, proposes a score-guidance to decide the use of bezlotoxumab, based on a points-based score, in which risk factors and patient conditions do not receive the same weight. We believe that age $>65$ years, immunodeficiency, a severe or persistent disease and an amplification cycle of the PCR $<24$ should be scored with one point each. Diseases or situations such as episodes of CDI in the previous year, malignant underlying diseases, inflammatory bowel disease and liver cirrhosis, should be scored with two points each. Finally, patients with hypertoxigenic or very virulent strains and diseases in which a FMT is indicated and cannot 
be performed or in which a previous FMT has failed, should receive 3 points with each of these conditions. In our opinion, patients who accumulate 3 or more points are clear candidates to receive bezlotoxumab, but this score has not been validated. Patients with lower scores, in our opinion, should be considered individually. Whenever possible, concomitant antibiotics and acid-suppressing medications, specifically histamine blockers and PPIs, should be removed [205]. The table 1 summarizes this simple, bedside score system, applied to patients with CDI that could help select patients at most risk for CDI recurrence.

In conclusion, we believe that in our environment, bezlotoxumab should be administered to patients with an episode of CDI that are at high risk of recurrence. At present, after the recent introduction of the drug in the market, and for economic reasons, it is prudent to select patients with high risk of recurrence and for this we offer a risk score recommendation to select the more clear candidates.

\section{QUESTION 15. Are there additional immunotherapy- based options to address CDI?}

Immunotherapy consists on using passive immunization with antibody-based products against $C$. difficile surface proteins to complement the deficient immune response of the host [206]. Targeted antigens are usually toxins A and B (TcdA and $T c d B$ ) and the main objective of immunotherapy is usually the prevention of recurrences [206]. As described above, bezlotoxumab is the only antibody-based product approved for clinical use to prevent CDI recurrences to date [181].

Another form of immunotherapy, albeit with no proven efficacy to date, is the use of intravenous immunoglobulins (IVIG). IVIG have been used to treat the recurrence of CDI with various success rates. Thus far, randomized studies showing a clear benefit are lacking [182]. A prospective analysis with a small number of patients compared the outcomes between use or no use of IVIG. There were no statistical differences in clinical outcomes as measured by all-cause mortality, colectomies, and length of stay [207]. In intravenous formulations for antibody-based products, the latter must be transferred from the systemic circulation to the intestinal lumen. To eliminate this hurdle, oral formulations of IG have also been explored in hamsters [208].

In conclusion, intravenous immunoglobulins are currently not recommended as adjunctive therapy for CDI since there are no conclusive data that demonstrate their efficacy in the prevention of recurrences.

QUESTION 16. What is the current role of Fecal Microbiota Transplantation (FMT)?

Experience with FMT in refractory or recurrent cases of CDI has accumulated over the years. FMT restores gut microbiota diversity through implantation of donor stools into the gastrointestinal tract of patients with CDI. This treatment has shown good clinical response in adults with refractory or recurrent CDI with few reports of adverse events [209-214].

The FMT technique requires a careful selection of donors to avoid the transmission of any of the known enteric pathogens and potentially of other diseases, that usually leads to the rejection of practically nine out of 10 donor candidates [215]. The reasons for rejection are multiple and include, for example, people who have had tattoos or acupuncture in the last six months or who have travelled to tropical countries in the last half year and those with a body mass index greater than 25 [211]. Today, there is a tendency to rely on repeated donations from a few very well-controlled donors who can supply efficient banks.

Fecal processing is cumbersome and unpleasant, and each donation provides material for approximately two to five transplants. At first, FMTs were performed with fresh material, administered either topically by colonoscopy or by nasoduodenal catheterization, using a minimum of 30 grams of fecal matter. Subsequently, the major milestones to facilitate the process have been to demonstrate that frozen faeces from healthy donors maintain their properties and efficacy and that encapsulated material, either fresh or lyophilized, administered orally in capsules, is as effective as the colonic delivery [26, 216-219].

Liofilization allows preparation and storage for multiple transplants that can be performed almost immediately. This establishes the possibility of creating banks for FMT that permit procedures to be performed quickly after indication. At

\begin{tabular}{l|ll}
\hline Table 1 & Prediction score for recurrent C. difficile Infection \\
& & \\
\hline+1 point: & +2 points: & +3 points: \\
\hline$>65$ years & Previous CDI (previous year) & FMT failure \\
Immunosuppressed & IBD & Indication for FMT but not possible \\
Severe CDI & Malignancy & Hypervirulent strains \\
Antibiotics for other infections & Other high-risk medical conditions & Recurrent episode \\
Toxin B Ct $<24$ & & \\
Persistent diarrhea $>5$ days & & \\
\hline
\end{tabular}

CDI: Clostridioides difficile infection, IBD: Inflammatory Bowel Disease, FMT: Fecal Material Transplantation. 
present, the administration of four capsules of lyophilized material in a single dose is sufficient $[34,217,220]$.

Some commercial companies have made available preparations of fecal material or even preparations of intestinal bacterial pools with satisfactory results [221].

In a recent systematic review [222] that included 37 studies (seven randomised controlled trials and 30 case series), FMT was more effective than vancomycin and the overall case resolution was $92 \%$. In cases of initial failure, consecutive courses of FMT resulted in an incremental effect. Recently, however, a tappering cycle of vancomycin was shown, in a comparative study, to be as effective as an FMT [223], however, the authors selected a suboptimal FMT delivery.

There is a general concern regarding long term safety in patients receiving FMT, particularly in relation to metabolic or immune-based disorders [21]. In an open-label, randomized, controlled trial, and in a systematic review that included 273 patients from 11 studies involving more than 10 analyzed cases each, the short-term safety and acceptability of the technique by the patients was high $[224,225]$. The transmission of potential pathogens or resistant microorganisms through faeces has been a cause for concern from the outset, but this risk has been minimal to date $[226,227]$. Also of concern is the risk of bacterial translocation with distant infections such as bacteremia in immunodeficient patients or in those with increased enteric barrier permeability. It is recommended to avoid FMT in patients with anaphylactic reactions due to food allergies and to be cautious in patients with decompensated cirrhosis or deeply immunocompromised.

Therefore, in the opinion of this working group, the indications for FMT would be focused on patients with proven recurrences and potentially in cases with poor response to treatment, particularly in patients with severe manifestations and who have failed in tappering treatments with vancomycin or fidaxomycin, as long as the procedure is available, the patient accepts it and none of the exclusion criteria for the procedure are met. At the present time, the indication of FMT for first episodes of CDI has yet to be considered an investigational procedure.

In conclusion, FMT is unquestionably one of the most effective ways to avoid the recurrence of CDI and should be offered to patients with multiple recurrences, particularly to those that failed a tappered cycle of oral vancomycin or fidaxomicin. Uncertainties remain about the standardization of the procedure and particularly about its long-term safety. It is also necessary to study the best combination of FMT with other available therapeutic procedures

QUESTION 17. In which situations should surgical intervention be considered?

Patients with severe complicated or fulminant CDI that do not respond to medical treatment in the first 24-48 hours should be evaluated by a surgeon. A classic review showed data supporting total colectomy with end ileostomy as the primary surgical treatment for patients with severe CDI [228]. However, total colectomy is associated with poor outcomes, signficiant morbidity, and a high mortality rate ranging from 35\% to $80 \%$ [229]. An alternative to a total colectomy procedure, diverting loop ileostomy, combined with colonic lavage, is a less aggressive alternative [229]. Briefly, this technique consists on performing a diverting loop ileostomy and using mechanical lavage to remove bacteria and toxins from the intestinal lumen, followed by a direct instillation of vancomycin into the lumen to further eliminate the remaining CD. This technique has a significantly lower mortality rate when compared with total colectomy and preservation of the colon was achieved in 39 of 42 patients (93\%) $[229,230]$. In a retrospective multicenter study including data from ten centers of patients who presented with CDI requiring surgery, when comparing colectomy and loop ileostomy, adjusted mortality was significantly lower in the loop ileostomy group [231]. In a more recent metaanalysis, however, it did not appear that diverting loop ileostomy was clearly assoociated with a decrease in mortality but resulted in increased rates of colonic preservation, restoration of intestinal continuity, and laparoscopic surgery[232].

In conclusion, current therapeutical options have reduced the need to resort to surgical invervention, relegating this option to fulminant, non-responding cases. Patients with CDI that do not respond to treatment in the first 24-48hrs should be evaluated by a surgeon; loop ileostomy and colonic lavage should be considered in severe complicated or fulminant CDI without response to medical treatment. Total colectomy should be avoided if at all possible.

\section{QUESTION 18. What is the situation of the vaccines in} the near future?

Vaccine candidates based on altered $C D$ toxins $A$ and $B$ are currently under clinical trial study for the prevention of CDI $[233,234]$. Early trials suggest that some of these candidates have an acceptable safety and tolerability profile. However, while select candidates have demonstrated substantial immune response in subjects, a definite dose-response relationship has not been established yet and as a result, the ideal dose remains unknown [190]. There is also some concern related to the short durability of the antibody response with some of these candidates, as this would potentially require the administration of additional doses or boosters to provide patients with a longterm clinical benefit $[190,235,236]$. The target population for vaccine administration requires careful consideration, highrisk groups such as subjects with compromised immunity and the elderly might benefit more, however, data on these populations is lacking [190]. The cost of a vaccination regime must also be considered, particularly if targeted to a high-risk population; as high prices might preclude implementation of this strategy in large groups for the prevention of CDI. Results from ongoing trials will be needed to determine whether vaccines constitute a long-term, cost-effective solution to prevent CDI.

In conclusion, vaccine candidates constitute a promi- 
sing solution to prevent CDI, however, substantial clinical trials are necessary to establish the real benefit associated to their use.

\section{QUESTION 19. Can probiotics be used to prevent re- currences?}

There is limited clinical evidence related to the use of probiotics in the treatment of CDI. In a meta-analysis, Saccharomyces boulardii showed promise for the prevention of CDI recurrences [237]. Another meta-analysis suggested that primary intervention of $\mathrm{CDI}$ with specific probiotic agents may be achievable [238]. However, a Cochrane review did not find sufficient evidence for the recommendation of probiotics as adjuvant therapy for CDI [239]. Furthermore, a multicenter, randomized, double-blind, placebo-controlled, trial performed to assess the role of Lactobacilli and Bifidobacteria in the prevention of antibiotic-associated diarrhea and CDI in older inpatients failed to demonstrate a beneficial effect with probiotics [240]. Even, a recent study shows that the use of probiotics was associated with a higher risk of recurrence [241].

In conclusion, probiotics cannot be recommended for widespread use for the prevention or adjuvant therapy of CDI.

\section{QUESTION 20. How should a patient with a first epi-} sode of CDI be managed?

As we previously concluded in question 11, recent literature and guidelines have implicitly agreed that metronidazole should be dismissed as an alternative for the treatment of CDI, even in non-severe cases $[21,162]$. In fact, the current approach for treating a first episode of CDI should not be based on the severity of the first episode but instead should be based on the presence or not of risk factors for CDI recurrence (figure 3).
With the recent evidence, it seems reasonable and cost-effective to treat a first episode with a low risk for recurrence with vancomycin orally (125 mg four times daily for 10 days) [154, 155]. In a few exceptions, i.e. if the patient has no ability for oral intake, should IV metronidazole be considered.

On the contrary, a first episode with a high risk for recurrence deserves a treatment that has proven to reduce CDI recurrences (i.e. fidaxomicin or bezlotoxumab). Therefore, in our opinion, the current debate consists on trying to identify the patient that, in the presence of a first episode, has a high risk for recurrence and could benefit from new treatment strategies to reduce future recurrences. As we mentioned before, scores for risk factors are needed, and we proposed in question 14 an example of a scoring system for determinig the use of bezlotoxumab in patients at high risk for recurrence (table 1).

Given the demonstrated efficacy of bezlotoxumab in the prevention of recurrent $C D I$ episodes, a regime of oral vancomycin (125 mg four times daily for 10 days) with bezlotoxumab (one dose of $10 \mathrm{mg} / \mathrm{kg} \mathrm{IV}$ ) as adjuvant therapy should be administered for a first episode with a high recurrence risk [183]. A regime of fidaxomicin is also an option in patients with a high risk for recurrence (200 mg twice daily for 10 days), however, it remains a price-sensitive option [160].

Recently, Rubio-Terrés et al. performed a cost-effectiveness analysis in Spain, comparing extended-pulsed fidaxomicin versus vancomycin in patients 60 years and older with CDI. According to their economic model, and the assumptions based on the Spanish National Health Ssystem fidaxomicin is cost-effective compared with vancomycin for the first-line treatment of CDI in patients aged 60 years and older [242].

In MODIFY studies it could not be confirmed that bezlotoxumab reduced the risk of recurrence in patients treated with fidaxomicin, probably because of the small number of

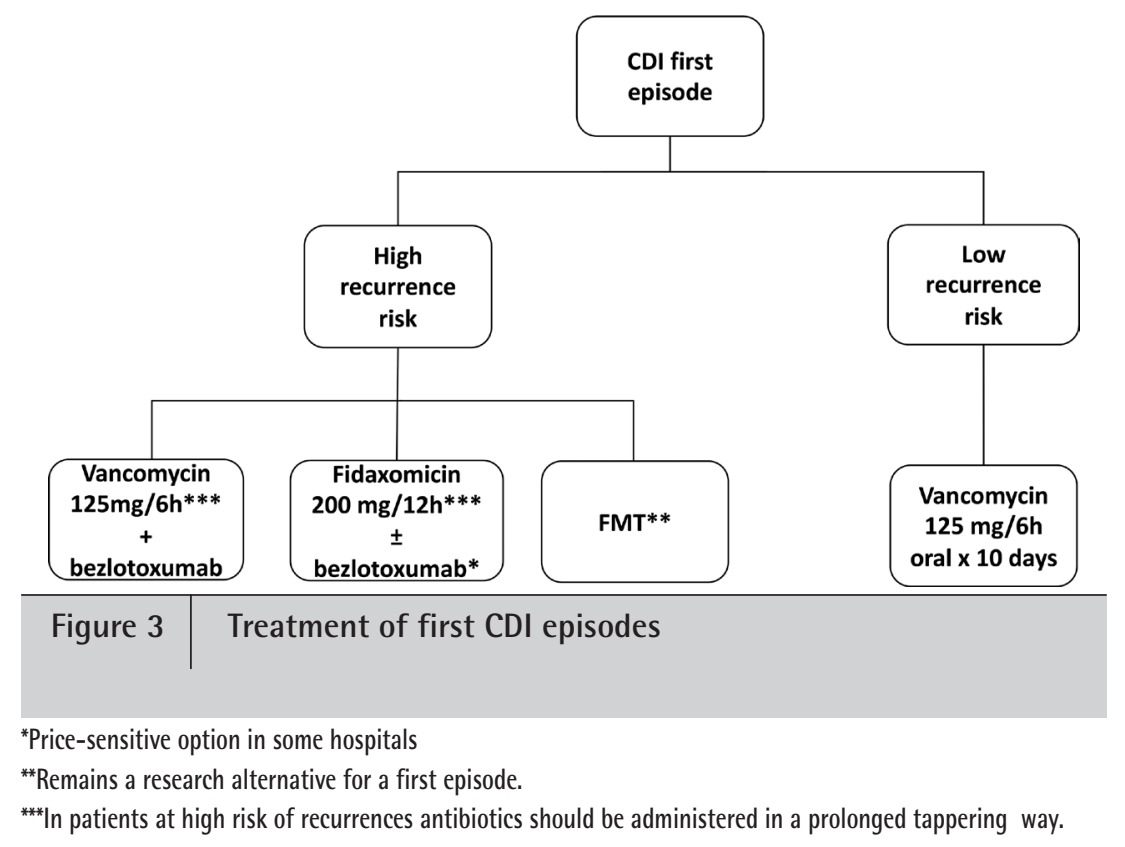


patients treated with this drug. Addition of bezlotoxumab to fidaxomicin is another treatment option [183], but it would still be affected by the same cost issues faced by the antibiotic alone and more studies are needed to evaluate the efficacy of reducing $\mathrm{rCDI}$ with this combination. The use of FMT, in the first episode with high-risk of recurrence, as we mentioned before, is yet only a research alternative. Purportedly, in a setting without economical restrictions, patients at higher risk for recurrence would benefit from fidaxomicin, the best antibiotic option to treat CDI, plus bezlotoxumab, a monoclonal antibody with antitoxin activity.

In conslusion, patients with a first CDI episode and a low risk for recurrence will benefit from oral vancomycin alone. In the case of the presence of high risk factors for recurrence, patients with a first CDI episode will benefit from adding bezlotoxumab or using fidaxomicin.

\section{QUESTION 21. How should a patient with a CDI recu- rrence be treated?}

Ideally, rCDI is a condition to prevent, more than a condition to treat. From a clinical and epidemiological point of view, a recurrence is conventially defined as a CDI episode that re-occurs within eight weeks after complete resolution of the initial or previous episode, confirmed by toxin detection in a stool sample. This definition has been accepted because it is clinically practical and easy to apply; however, patients with previous episodes not considered recurrences because of the time between one episode and the next, should still be managed as patients at high risk for recurrences [194]. The risk of recurrence is variable, ranging between 15\% and 25\% after the initial episode, reaching rates of up to $60 \%$ after a third episode $[11,243,244]$.

Treatment options for patients that have recurred are the same as for patients with a first episode with a high risk for recurrence (i.e. fidaxomicin, bezlotoxumab and/or FMT). Recurrence is the highest indicator that a patient needs to be managed focused in preventing recurrences. In these cases, there are different alternatives for treatment that could be applied; i.e. extending or prolonging CDI antibiotic treatment, enhancing the immune system against toxins with bezlotoxumab or microbiota restoration with FMT.

Extending the suppression of CD has been evaluated with strategies that have demonstrated to reduce CDI recurrences. That is the case of vancomycin tapering or fidaxomicin extended treatment. With vancomycin tapering, these regimens typically include a 10- to 14-day course of oral vancomycin at a dose of $125 \mathrm{mg}$ four times per day, followed by a tapering dose over two weeks, followed by "pulsed" dosing with $125 \mathrm{mg}$ once every two or three days for two to eight weeks $[223,245]$ The other alternative, is a regime of extended-pulsed fidaxomicin: $200 \mathrm{mg}$ oral tablets, twice daily on days $1-5$, then once daily on alternate days on days 7-25. This strategy has been compared with standard vancomycin, demonstrating superiority of fidaxomicin regarding sustained cure of $\mathrm{CDI}$ and lower rates of recurrence [246].
A controlled clinical trial comparing fidaxomicin extended versus a regimen of vancomycin taper would further support these strategies.

Adding bezlotoxumab to the antimicrobial CDI treatment of patients who already have had a recurrence has proven to reduce CDI recurrences [183]. Additionally, it seems reasonable to considerer giving another dose of bezlotoxumab in a patient with a recurrence in which the monoclonal antibody may have been metabolized since the first episode and the cause of CDI persists (i.e. continuous use of antibiotics). However, there is a need for studies that evaluate the efficacy of repeating a bezlotoxumab dose in a patient who has received the monoclonal antibody for a previous episode. This repetition is not approved.

FMT has also demonstrated efficacy in the treatment of recurrences and should be considered in centers where the procedure is standardized [21]. It is currently uncertain how FMT should be linked to other treatment options; i.e. previous preparation with vancomycin or fidaxomicin before the FMT. These are gaps that must be addressed and evaluated in future studies.

Another situation are the patients with multiple recurrences. These patients enter in a loop of recurrences, receiving numerous treatment options for CDI that are not able to stop the recurrence cycle. The main cause of this situation is the persistence of one or more risk factors for CDI recurrence, i.e. continuous antibiotic use for other infections, persistent immunosuppressive therapy, etc. [247]. In these patients the best treatment options that have proven to reduce CDI recurrences should be used. The management of these patients consist of an art between using the current options for treating rCDI and the experience of the physician. The three available ammunitions (fidaxomicin, bezlotoxumab and FMT) must be used in these scenarios. In our opinion, these patients would benefit from the best antibiotic against $C D$ recurrence (fidaxomicin), immunity against $\mathrm{CD}$ toxin $\mathrm{B}$ (bezlotoxumab) and restoration of the gut microbiota (FMT).

In conclusion treatment options for patients that have recurred are the same as for patients with a first episode with a high risk for recurrence. However, a different management can be applied (i.e vancomycin taper regime or extended pulse of fidaxomicin). In these patients, in our opinion, FMT is the treatment of choice but the association of bezlotoxumab for immunity against toxin B must be considered. Whenever possible, risk factors for CDI recurrence should be halted in order to prevent future recurrences.

QUESTION 22. In patients that have recurrent episodes of CDI induced by new courses of systemic antibiotics, is oral vancomycin prophylaxis effective?

One of the first studies addressing this matter was the retrospective study performed by Carignan et al. in 2016 [248] in which they studied $551 \mathrm{CDI}$ episodes and observed that oral vancomycin prophylaxis decreased the risk of further recurren- 
ce in patients who had a former rCDI episode (AHR, 0.47; 95\% $\mathrm{Cl}, 0.32-0.69 ; \mathrm{P}<0.0001)[248]$. This reduction was not observed for primary CDI episodes.

More recently, in 2019, two new studies have been published. Knight et al. evaluated retrospectively the long-term efficacy of oral vancomycin prophylaxis in preventing CDI recurrence in subjects who require subsequent antibiotic exposure. They observed that CDI recurrence within 12 months was significantly lower in subjects receiving oral vancomycin prophylaxis compared to those who did not receive it $(6.3 \%$ vs 28.8\%; odds ratio (OR): 0.16; 95\% confidence interval (CI): $0.04-0.77 ; P=0.011)$ [249]. Zhang et al. presented a small series of patients in which they observed that prolonged vancomycin prophylaxis at a dose of $125 \mathrm{mg}$ orally daily was an effective and well-tolerated option for secondary prevention of rCDI [250].

Several recent communications have been made at the Infectious Diseases Week meeting, held in Washington (ID Week) in October 2019, providing more evidence on this matter. Two retrospective studies $[251,252]$ including 72 and 264 patients, respectively, evaluated the use of prophylaxis with oral vancomycin, $125 \mathrm{mg}$ twice daily in patients with a history of CDI and observed that the incidence of CDI was significantly lower in the group receiving oral prophylaxis compared to the control group.

A randomized, prospective study was presented by Johnson et al., in which 100 patients were enrolled 1:1 to either oral vancomycin (dosed at $125 \mathrm{mg}$ once daily while receiving systemic antibiotics and continued for 5 days post completion of systemic antibiotics), or no prophylaxis. No cases of rCDI were diagnosed in the prophylaxis group compared to 6 (12\%) in the no prophylaxis group $(p=0.03)$ [253]. As can be noted, there is still limited data regarding this issue, and more randomized controlled trials are needed. However, the existing literature holds promise for the use of oral vancomycin prophylaxis when a subsequent antimicrobial therapy is planned in a high-risk of rCDI patient.

In conclusion, antibiotic prophylaxis cannot be recommended for widespread use for the prevention of rCDI, however in selected cases that fulfill a high risk profile for rCDI and are scheduled to receive systemic antimicrobials, it can be indicated.

\section{SUMMARY}

1. CDI should be suspected in all diarrheic episodes of patients of any age, with or without traditional risk factors for CDI. except for those younger than 2 years.

2. One stool specimen is the best cost-effective number needed for the diagnosis of CDI.

3. Both, samples without any transport medium and samples with transport medium for aerobic enteropathogens, as Cary-Blair, are suitable for the diagnosis of CDI.

4. Microbiologists in the laboratory can have an important role in the improvement of the CDI diagnosis by processing unformed stool specimens from patients older than 2 years, independently of the request by the clinicians.

5. Rectal specimens are useful for CDI diagnosis in patients whose stool specimens cannot be obtained. Stool specimens are more sensitive than colonic biopsies for the diagnosis of CDI.

6. Detection of GDH by EIA as screening test, followed by a rapid confirmatory technique as a NAAT alone or together with a toxin $A$ and $B$ EIA, and the use of toxigenic culture, is the optimal diagnostic combination of laboratory tests to diagnose CDI.

7. Tests of antibiotic susceptibility should be performed annually to detect the emergence of resistance in reference laboratories or in specific situations but not in a daily regular basis.

8. Detection of toxigenic $C$. difficile from stool specimens is not adequate as a follow-up method for the evolution of patients with CDI.

9. Rapid laboratory work-up and reporting of tests for toxigenic $C$. difficile is crucial for the control and management of this illness.

10. The basic support approach for patients with CDI includes: fluids and electrolyte replacement, and removal of intestinal peristalsis inhibitors, antacid medication, and concomitant antibiotics, when feasible.

11. Oral vancomycin is the recommended drug for an initial CDI episode; oral fidaxomicin or bezlotoxumab, should be considered in initial CDI episodes with a high risk of recurrence. Metronidazole should be restricted to situations in which vancomycin or fidaxomicin are contraindicated or an oral administration is not possible.

12. Rifaximin, nitazoxamide, fusidic acid, tygecicline, and teicoplanin are currently not considered as therapy options for CDI. Ridinilazole is a promising antibiotic with phase 3 clinical trials set to start in 2019 to demonstrate non-inferiority over vancomycin for the treatment of CDI.

13. Bezlotoxumab is the first approved treatment for the prevention of $\mathrm{CDI}$ recurrence, with a demonstrated higher efficacy in all sub-groups of patients at greater risk for recurrence.

14. Bezlotoxumab should be administered to patients with episodes of CDI that are at high risk of recurrence. We suggest that, despite limitations, risk scores should be used to optimize candidate selection.

15. Given the lack of conclusive data, intravenous immunoglobulins are currently not recommended as adjunctive therapy.

16. FMT should be offered to patients with multiple recurrences, particularly to those who failed a tapered cycle of oral vancomycin or fidaxomicin. Uncertainties remain about the standardization of the procedure and particularly about its long-term safety.

17. Surgery should be considered in those patients with CDI that do not respond to treatment in the first 24-48hrs; 
loop ileostomy and colonic lavage should be considered in severe complicated or fulminant CDI without response to medical treatment.

18. Vaccines constitute a promising solution to prevent CDI, however, substantial clinical trials are necessary to establish the real benefit associated to their use.

19. Probiotics cannot be recommended for the prevention or adjuvant therapy of CDI.

20. Patients with a first CDI episode and a low risk for recurrence will benefit from a 10 day course of oral vancomycin. In the case of the presence of high risk factors for recurrence, patients with a first CDI episode should be treated with bezlotoxumab and/fidaxomicin.

21. Recurrences, always imply a high risk of new recurrences and should be treated as such. FMT in these circumstances is probably the treatment of choice. Other options are a vancomycin or fidaxomicin tapering regimes with bezlotoxumab as adjuvant therapy. Whenever possible, risk factors for CDI recurrence should be halted in order to prevent future recurrences.

22. In patients with a history of CDI recurrence in coincidence with the re-introductrion of systemic antibiotics prevention with oral vancomycin (125 mg per day, during the days of use of systemic treatment and for up to 5 days after systemic antibiotics are completed) may be considered.

\section{REFERENCES}

1. Ofosu A. Clostridium difficile infection: a review of current and emerging therapies. Ann Gastroenterol. 2016;29(2):147-54. DOI: 10.20524/aog.2016.0006

2. Bouza E, Marin M, Pelaez T, Alcala L. The situation and management of Clostridium difficile infection in Spain: an opinion document. Rev Esp Quimioter. 2013;26(3):261-86. PMID: 24080894

3. Olesen B, Hallberg H, Bangsborg J, Jensen JN, Jarlov JO. A new approach to recognition of Clostridium difficile infections with community onset. Clin Microbiol Infect. 2015;21(8):e55-6. D0I: 10.1016/j.cmi.2015.04.006

4. Ogielska M, Lanotte P, Le Brun C, Valentin AS, Garot D, Tellier AC, et al. Emergence of community-acquired Clostridium difficile infection: the experience of a French hospital and review of the literature. Int J Infect Dis. 2015;37:36-41. DOI: 10.1016/j.ijid.2015.06.007

5. Borali E, Ortisi G, Moretti C, Stacul EF, Lipreri R, Gesu GP, et al. Community-acquired Clostridium difficile infection in children: A retrospective study. Dig Liver Dis. 2015;47(10):842-6. DOI: 10.1016/j.dld.2015.06.002

6. Reigadas E, Alcala L, Marin M, Burillo A, Munoz P, Bouza E. Missed diagnosis of Clostridium difficile infection; a prospective evaluation of unselected stool samples. J Infect. 2015;70(3):264-72. DOI: 10.1016/j.jinf.2014.10.013

7. Guh AY, Adkins SH, Li Q, Bulens SN, Farley MM, Smith Z, et al. Risk Factors for Community-Associated Clostridium difficile Infection in Adults: A Case-Control Study. Open Forum Infect Dis. 2017;4(4):ofx171. DOI: 10.1093/ofid/ofx171

8. Alcala L, Reigadas E, Marin M, Martin A, Catalan P, Bouza E. Impact of clinical awareness and diagnostic tests on the underdiagnosis of Clostridium difficile infection. Eur J Clin Microbiol Infect Dis. 2015;34(8):1515-25. DOI: 10.1007/s10096-015-2380-3

9. Alcala L, Martin A, Marin M, Sanchez-Somolinos M, Catalan P, Pelaez $T$, et al. The undiagnosed cases of Clostridium difficile infection in a whole nation: where is the problem? Clin Microbiol Infect. 2012;18(7):E204-E13. DOI: 10.1111/j.1469-0691.2012.03883.x

10. Alcala L, Marin M, Martin A, Sanchez-Somolinos M, Catalan P, Pelaez MT, et al. Laboratory diagnosis of Clostridium difficile infection in Spain: a population-based survey. J Hosp Infect. 2011;79(1):137. DOI: 10.1016/j.jhin.2011.05.017

11. Rodriguez-Pardo D, Almirante B, Bartolome RM, Pomar V, Mirelis B, Navarro F, et al. Epidemiology of Clostridium difficile infection and risk factors for unfavorable clinical outcomes: results of a hospitalbased study in Barcelona, Spain. J Clin Microbiol. 2013;51(5):146573. DOI: $10.1128 / \mathrm{jcm} .03352-12$

12. Davies KA, Longshaw CM, Davis GL, Bouza E, Barbut F, Barna Z, et al. Underdiagnosis of Clostridium difficile across Europe: the European, multicentre, prospective, biannual, point-prevalence study of Clostridium difficile infection in hospitalised patients with diarrhoea (EUCLID). Lancet Infect Dis. 2014; 14(12):1208-19. DOI: 10.1016/s1473-3099(14)70991-0

13. Larrainzar-Coghen $T_{1}$ Rodriguez-Pardo $D$, Puig-Asensio $M$, Rodriguez V, Ferrer $C$, Bartolome R, et al. First recurrence of Clostridium difficile infection: clinical relevance, risk factors, and prognosis. Eur J Clin Microbiol Infect Dis. 2016;35(3):371-8. DOI: 10.1007/s10096015-2549-9

14. Bouza E. Consequences of Clostridium difficile infection: understanding the healthcare burden. Clin Microbiol Infect. 2012;18 Suppl 6:5-12. DOI: 10.1111/1469-0691.12064

15. Olsen MA, Yan Y, Reske KA, Zilberberg M, Dubberke ER. Impact of Clostridium difficile recurrence on hospital readmissions. Am J Infect Control.43(4):318-22.

16. Wilcox MH, Ahir H, Coia JE, Dodgson A, Hopkins $S$, Llewelyn MJ, et al. Impact of recurrent Clostridium difficile infection: hospitalization and patient quality of life. J Antimicrob Chemother. 2017;72(9):2647-56. DOI: 10.1093/jac/dkx174

17. Frederic Barbut TG, Philippe Vanhems, Alban Le Monnier, Viviane Jeanbat, Anne Duburcq, Sarah Alami, Caroline Bensoussan, Francis Fagnani. Impact of Clostridium difficile Infections on Patients' Quality of Life: a French Hospital Prospective Study. Open Forum Infect Dis. 2017;4(Suppl 1):S393-S4. DOI: 10.1093/ofid/ofx163.979

18. Wilcox MH. Laboratory diagnosis of Clostridium difficile infection: in a state of transition or confusion or both? J Hosp Infect. 2011;79(1):1-3. DOI: 10.1016/j.jhin.2011.05.010

19. Alcala-Hernandez L, Mena-Ribas A, Niubo-Bosh J, Marin-Arriaza M. [Laboratory diagnosis of Clostridium difficile infection]. Enferm Infecc Microbiol Clin. 2016;34(9):595-602. D0I: 10.1016/j.eimc.2015.09.004

20. Debast SB, Bauer MP, Kuijper EJ. European Society of Clinical Microbiology and Infectious Diseases: update of the treatment guidance document for Clostridium difficile infection. Clin Microbiol Infect. 2014;20 Suppl 2:1-26. DOI: 10.1111/1469-0691.12418

21. McDonald LC, Gerding DN, Johnson S, Bakken JS, Carroll KC, Coffin 
SE, et al. Clinical Practice Guidelines for Clostridium difficile Infection in Adults and Children: 2017 Update by the Infectious Diseases Society of America (IDSA) and Society for Healthcare Epidemiology of America (SHEA). Clin Infect Dis. 2018;66(7):987-94. DOI: 10.1093/cid/ciy149

22. Louie TJ, Miller MA, Mullane KM, Weiss K, Lentnek A, Golan Y, et al. Fidaxomicin versus vancomycin for Clostridium difficile infection. N Engl J Med. 2011;364(5):422-31. DOI: 10.1056/NEJMoa0910812

23. Cornely OA, Crook DW, Esposito R, Poirier A, Somero MS, Weiss $K_{1}$ et al. Fidaxomicin versus vancomycin for infection with Clostridium difficile in Europe, Canada, and the USA: a double-blind, non-inferiority, randomised controlled trial. Lancet Infect Dis. 2012. DOI: 10.1016/s1473-3099(11)70374-7

24. Wilcox M, Dorr MB, Pedley A. Bezlotoxumab and Recurrent Clostridium difficile Infection. N Engl J Med. 2017;376(16):1594-6. DOI: 10.1056/NEJMc1702531

25. Zellmer C, De Wolfe TJ, Van Hoof S, Blakney R, Safdar N. Patient Perspectives on Fecal Microbiota Transplantation for Clostridium difficile Infection. Infect Dis Ther. 2016;5(2):155-64. DOI: 10.1007| s40121-016-0106-1

26. Lee $\mathrm{CH}$, Steiner T, Petrof EO, Smieja M, Roscoe D, Nematallah A, et al. Frozen vs Fresh Fecal Microbiota Transplantation and Clinical Resolution of Diarrhea in Patients With Recurrent Clostridium difficile Infection: A Randomized Clinical Trial. JAMA. 2016;315(2):142-9. DOI: 10.1001/jama.2015.18098

27. Gupta $\mathrm{S}$, Allen-Vercoe E, Petrof EO. Fecal microbiota transplantation: in perspective. Therap Adv Gastroenterol. 2016;9(2):229-39. DOI: $10.1177 / 1756283 \times 15607414$

28. Juul FE, Garborg K, Bretthauer M, Skudal H, Oines MN, Wiig H, et al. Fecal Microbiota Transplantation for Primary Clostridium difficile Infection. N Engl J Med. 2018. D0I: 10.1056/NEJMc1803103

29. Martinez C, Edwards J, Hassoun A. Commercialized fecal microbiota transplantation provides efficacious treatment of Clostridium difficile infection. Infect Dis (Lond). 2018;50(11-12):864-7. DOI: 10.1080/23744235.2018.1500709

30. Azimirad M, Yadegar A, Asadzadeh Aghdaei H, Kelly CR. Enterotoxigenic Clostridium perfringens Infection as an Adverse Event After Faecal Microbiota Transplantation in Two Patients With Ulcerative Colitis and Recurrent Clostridium difficile Infection: A Neglected Agent in Donor Screening. J Crohns Colitis. 2019. DOI: 10.1093/ecco-jcc/jjz006

31. Vigvari S, Vincze A, Solt J, Sipos D, Feiszt Z, Kovacs B, et al. Experiences with fecal microbiota transplantation in Clostridium difficile infections via upper gastrointestinal tract. Acta Microbiol Immunol Hung. 2018:1-10. DOI: 10.1556/030.65.2018.051

32. Hibbard J, Jiang ZD, DuPont HL. Fecal Calprotectin and Fecal Indole Predicts Outcome of Fecal Microbiota Transplantation in Subjects with Recurrent Clostridium difficile Infection. Anaerobe. 2019. DOI: 10.1016/j.anaerobe.2019.03.006

33. Hota SS, Poutanen SM. Fecal microbiota transplantation for recurrent Clostridium difficile infection. Cmaj. 2018;190(24):E746. DOI: 10.1503/cmaj.171454

34. Reigadas E, Olmedo M, Valerio M, Vazquez-Cuesta S, Alcala L, Marin $M_{1}$ et al. Fecal microbiota transplantation for recurrent Clostridium difficile infection: Experience, protocol, and results. Rev Esp Quimioter. 2018;31(5):411-8. PMC:6194865

35. Hvas $C L$, Dahl Jorgensen $S M$, Jorgensen $S P$, Storgaard $M$, Lemming L, Hansen MM, et al. Fecal Microbiota Transplantation Is Superior to Fidaxomicin for Treatment of Recurrent Clostridium difficile Infection. Gastroenterology. 2019. DOI: 10.1053/j.gastro.2018.12.019

36. Pringle PL, Soto MT, Chung RT, Hohmann E. Patients With Cirrhosis Require More Fecal Microbiota Capsules to Cure Refractory and Recurrent Clostridium difficile Infections. Clin Gastroenterol Hepatol. 2019;17(4):791-3. DOI: 10.1016/j.cgh.2018.05.038

37. Shogbesan O, Poudel DR, Victor S, Jehangir A, Fadahunsi O, Shogbesan $\mathrm{G}$, et al. A Systematic Review of the Efficacy and Safety of Fecal Microbiota Transplant for Clostridium difficile Infection in Immunocompromised Patients. Can J Gastroenterol Hepatol. 2018;2018:1394379. DOI: 10.1155/2018/1394379

38. Sheldon E, Kitchin N, Peng Y, Eiden J, Gruber W, Johnson E, et al. A phase 1, placebo-controlled, randomized study of the safety, tolerability, and immunogenicity of a Clostridium difficile vaccine administered with or without aluminum hydroxide in healthy adults. Vaccine. 2016;34(18):2082-91. DOI: 10.1016/j.vaccine.2016.03.010

39. Ghose C, Kelly CP. The prospect for vaccines to prevent Clostridium difficile infection. Infect Dis Clin North Am. 2015;29(1):145-62. DOI: 10.1016/j.idc.2014.11.013

40. McFarland LV, Surawicz CM, Stamm WE. Risk factors for Clostridium difficile carriage and $\mathrm{C}$. difficile-associated diarrhea in a cohort of hospitalized patients. J Infect Dis. 1990;162(3):678-84.

41. Henrich TJ, Krakower D, Bitton A, Yokoe DS. Clinical risk factors for severe Clostridium difficile-associated disease. Emerg Infect Dis. 2009;15(3):415-22.

42. McFarland LV. Diarrhoea associated with antibiotic use. Bmj. 2007;335(7610):54-5.

43. Louie TJ, Meddings J. Clostridium difficile infection in hospitals: risk factors and responses. Cmaj. 2004;171(1):45-6.

44. Lai KK, Melvin ZS, Menard MJ, Kotilainen HR, Baker S. Clostridium difficile-associated diarrhea: epidemiology, risk factors, and infection control. Infect Control Hosp Epidemiol. 1997;18(9):628-32.

45. Johnson S, Samore MH, Farrow KA, Killgore GE, Tenover FC, Lyras $D$, et al. Epidemics of diarrhea caused by a clindamycin-resistant strain of Clostridium difficile in four hospitals. N Engl J Med. 1999;341(22):1645-51.

46. Bartlett JG, Perl TM. The new Clostridium difficile--what does it mean? N Engl J Med. 2005;353(23):2503-5.

47. Bartlett JG. Clinical practice. Antibiotic-associated diarrhea. N Engl J Med. 2002;346(5):334-9.

48. Bartlett JG. How to identify the cause of antibiotic-associated diarrhea. The Journal of critical illness. 1994;9(12):1063-7.

49. Khanna S, Pardi DS, Aronson SL, Kammer PP, Orenstein R, St Sauver JL, et al. The Epidemiology of Community-Acquired Clostridium difficile Infection: A Population-Based Study. Am J Gastroenterol. 2011. DOI: 10.1038/ajg.2011.398

50. Kuntz JL, Chrischilles EA, Pendergast JF, Herwaldt LA, Polgreen PM. Incidence of and risk factors for community-associated Clostri- 
dium difficile infection: A nested case-control study. BMC Infect Dis. 2011;11:194. DOI: 10.1186/1471-2334-11-194

51. Naggie S, Miller BA, Zuzak KB, Pence BW, Mayo AJ, Nicholson BP, et al. A case-control study of community-associated Clostridium difficile infection: no role for proton pump inhibitors. Am J Med. 2011;124(3):276 e1-7. DOI: 10.1016/j.amjmed.2010.10.013

52. Reigadas E, Alcala L, Gomez J, Marin M, Martin A, Onori R, et al. Breakthrough Clostridium difficile Infection in Cirrhotic Patients Receiving Rifaximin. Clin Infect Dis. 2018;66(7):1086-91. DOI: 10.1093/cid/cix918

53. Fekety $R$, McFarland LV, Surawicz CM, Greenberg RN, Elmer GW, Mulligan ME. Recurrent Clostridium difficile diarrhea: characteristics of and risk factors for patients enrolled in a prospective, randomized, double-blinded trial. Clin Infect Dis. 1997;24(3):324-33. DOI: 10.1093/clinids/24.3.324

54. Fekety R. Guidelines for the diagnosis and management of Clostridium difficile-associated diarrhea and colitis. American College of Gastroenterology, Practice Parameters Committee. Am J Gastroenterol. 1997;92(5):739-50.

55. Wanahita A, Goldsmith EA, Marino BJ, Musher DM. Clostridium difficile infection in patients with unexplained leukocytosis. Am J Med. 2003;115(7):543-6.

56. Salcedo J, Keates S, Pothoulakis C, Warny M, Castagliuolo I, LaMont JT, et al. Intravenous immunoglobulin therapy for severe Clostridium difficile colitis. Gut. 1997;41(3):366-70. DOI: 10.1136/ gut.41.3.366

57. Fordtran JS. Colitis due to Clostridium difficile toxins: underdiagnosed, highly virulent, and nosocomial. Proc (Bayl Univ Med Cent). 2006;19(1):3-12. DOI: 10.1080/08998280.2006.11928114

58. Gonzalez-Del Vecchio M, Alvarez-Uria A, Marin M, Alcala L, Martin A, Montilla $\mathrm{P}$, et al. Clinical Significance of Clostridium difficile in Children Less Than 2 Years Old: A Case-Control Study. Pediatr Infect Dis J. 2016;35(3):281-5. DOI: 10.1097/INF.0000000000001008

59. Faust SN, Wilcox MH, Banaszkiewicz A, Bouza E, Raymond J, Gerding DN. Lack of evidence for an unmet need to treat Clostridium difficile infection in infants aged <2 years: expert recommendations on how to address this issue. Clin Infect Dis. 2015;60(6):9128. DOI: $10.1093 /$ cid/ciu936

60. Aichinger $E_{1}$ Schleck CD, Harmsen WS, Nyre LM, Patel R. Nonutility of repeat laboratory testing for detection of Clostridium difficile by use of PCR or enzyme immunoassay. J Clin Microbiol. 2008;46(11):3795-7.

61. van den Berg RJ, Vaessen N, Endtz HP, Schulin T, van der Vorm ER, Kuijper EJ. Evaluation of real-time PCR and conventional diagnostic methods for the detection of Clostridium difficile-associated diarrhoea in a prospective multicentre study. J Med Microbiol. 2007;56(Pt 1):36-42.

62. Cardona DM, Rand KH. Evaluation of repeat Clostridium difficile enzyme immunoassay testing. J Clin Microbiol. 2008;46(11):3686-9.

63. Cohen SH, Gerding DN, Johnson S, Kelly CP, Loo VG, McDonald LC, et al. Clinical practice guidelines for Clostridium difficile infection in adults: 2010 update by the society for healthcare epidemiology of America (SHEA) and the infectious diseases society of Ameri- ca (IDSA). Infect Control Hosp Epidemiol. 2010;31(5):431-55. DOI: 10.1086/651706

64. Crobach MJ, Dekkers OM, Wilcox MH, Kuijper EJ. European Society of Clinical Microbiology and Infectious Diseases (ESCMID): data review and recommendations for diagnosing Clostridium difficileinfection (CDI). Clin Microbiol Infect. 2009;15(12):1053-66.

65. Brook I. Anaerobic infections in childhood. Reviews of infectious diseases. 1984;6 Suppl 1:S187-92.

66. Carroll KC, Bartlett JG. Biology of Clostridium difficile: implications for epidemiology and diagnosis. Annu Rev Microbiol. 2011;65:50121. DOI: 10.1146/annurev-micro-090110-102824

67. Missaghi B, Valenti AJ, Owens RC, Jr. Clostridium difficile infection: a critical overview. Curr Infect Dis Rep. 2008;10(3):165-73.

68. Noren T. Clostridium difficile and the disease it causes. Methods Mol Biol.646:9-35.

69. DuPont HL. Approach to the patient with infectious colitis. Curr Opin Gastroenterol.28(1):39-46.

70. Cary SG, Blair EB. New Transport Medium for Shipment of Clinical Specimens. I. Fecal Specimens. J Bacteriol. 1964;88:96-8. 277262

71. Brown NA, Lebar WD, Young CL, Hankerd RE, Newton DW. Diagnosis of Clostridium difficile infection: comparison of four methods on specimens collected in Cary-Blair transport medium and tcdB PCR on fresh versus frozen samples. Infect Dis Rep.3(1):e5.

72. UK Government. www.gov.uk/government/uploads/system/ uploads/attachment_data/file/215135/dh_133016.pdf.

73. American Society for Microbiology. http://www.asm.org/images/ $\mathrm{pdf} /$ Clinical/clostridiumdifficile9-21.pdf13.

74. McFarland LV, Coyle MB, Kremer WH, Stamm WE. Rectal swab cultures for Clostridium difficile surveillance studies. J Clin Microbiol. 1987;25(11):2241-2.

75. Kundrapu S, Sunkesula VC, Jury LA, Sethi AK, Donskey CJ. Utility of perirectal swab specimens for diagnosis of Clostridium difficile infection. Clin Infect Dis.55(11):1527-30.

76. Bouza $E_{1}$ Alcala. L, Reigadas. E. Optimizing the diagnostic testing of Clostridium difficile infection. Expert Rev Anti Infect Ther. 2016;14(9):801-8.

77. Novak-Weekley SM, Marlowe EM, Miller JM, Cumpio J, Nomura JH, Vance $\mathrm{PH}$, et al. Clostridium difficile testing in the clinical laboratory by use of multiple testing algorithms. J Clin Microbiol.48(3):889-93.

78. Albright JB, Bonatti $H_{1}$ Mendez J, Kramer D, Stauffer J, Hinder R, et al. Early and late onset Clostridium difficile-associated colitis foIlowing liver transplantation. Transpl Int. 2007;20(10):856-66. DOI: 10.1111/j.1432-2277.2007.00530.x

79. Alcala L. Laboratory tests for diagnosis of Clostridium difficile infection: past, present, and future. Enferm Infecc Microbiol Clin. 2013;31(2):65-7. DOI: 10.1016/j.eimc.2012.10.003

80. Barbut $F$, Lalande $V$, Burghoffer $B$, Thien HV, Grimprel E, Petit JC. Prevalence and genetic characterization of toxin $A$ variant strains of Clostridium difficile among adults and children with diarrhea in France. J Clin Microbiol. 2002;40(6):2079-83.

81. Jakobsen L, Tvede M. [Pseudomembraneous colitis caused by a to- 
xin B-positive and a toxin A-negative strain of Clostridium difficile]. Ugeskr Laeger. 2006;168(17):1634-5.

82. Kim H, Riley TV, Kim M, Kim CK, Yong D, Lee K, et al. Increasing prevalence of toxin A-negative, toxin B-positive isolates of Clostridium difficile in Korea: impact on laboratory diagnosis. J Clin Microbiol. 2008;46(3):1116-7.

83. Stoddart B, Wilcox MH. Clostridium difficile. Curr Opin Infect Dis. 2002;15(5):513-8.

84. Chan EL, Seales D, Drum H. Comparing ImmunoCard with two EIA assays for Clostridium difficile toxins. Clin Lab Sci. 2009;22(2):81-5.

85. Schmidt ML, Gilligan PH. Clostridium difficile testing algorithms: what is practical and feasible? Anaerobe. 2009;15(6):270-3.

86. She RC, Durrant RJ, Petti CA. Evaluation of enzyme immunoassays to detect Clostridium difficile toxin from anaerobic stool culture. Am J Clin Pathol. 2009;131(1):81-4.

87. Carroll KC. Tests for the diagnosis of Clostridium difficile infection: the next generation. Anaerobe. 2011;17(4):170-4. doi: 10.1016/j. anaerobe.2011.01.002

88. Chapin KC, Dickenson RA, Wu F, Andrea SB. Comparison of five assays for detection of Clostridium difficile toxin. J Mol Diagn. 2011;13(4):395-400. doi: 10.1016/j.jmoldx.2011.03.004.

89. Alcala L, Marin M, Madrid M, Dominguez-Garcia E, Catalan P, Pelaez MT, et al. Comparison of ImmunoCard Toxins A\&tB and the new semiautomated Vidas Clostridium difficile Toxin A\&tB tests for diagnosis of C. difficile infection. J Clin Microbiol.2010; 48(3):1014-5. DOI: 10.1128/JCM.01642-09

90. Alcala L, Sanchez-Cambronero L, Catalan MP, Sanchez-Somolinos $M$, Pelaez MT, Marin M, et al. Comparison of three commercial methods for rapid detection of Clostridium difficile toxins $A$ and $B$ from fecal specimens. J Clin Microbiol. 2008;46(11):3833-5.

91. Snell $H_{1}$ Ramos $M_{1}$ Longo $S_{1}$ John $M$, Hussain Z. Performance of the TechLab C. DIFF CHEK-60 enzyme immunoassay (EIA) in combination with the $\mathrm{C}$. difficile Tox A/B II EIA kit, the Triage $\mathrm{C}$. difficile panel immunoassay, and a cytotoxin assay for diagnosis of Clostridium difficile-associated diarrhea. J Clin Microbiol. 2004;42(10):4863-5.

92. Zheng L, Keller SF, Lyerly DM, Carman RJ, Genheimer CW, Gleaves $C A$, et al. Multicenter evaluation of a new screening test that detects Clostridium difficile in fecal specimens. J Clin Microbiol. 2004;42(8):3837-40.

93. Belanger SD, Boissinot M, Clairoux N, Picard FJ, Bergeron MG. Rapid detection of Clostridium difficile in feces by real-time PCR. J Clin Microbiol. 2003;41(2):730-4.

94. Eastwood K, Else P, Charlett A, Wilcox M. Comparison of nine commercially available Clostridium difficile toxin detection assays, a real-time PCR assay for $\mathrm{C}$. difficile $t c d B$, and a glutamate dehydrogenase detection assay to cytotoxin testing and cytotoxigenic culture methods. J Clin Microbiol. 2009;47(10):3211-7.

95. Larson AM, Fung AM, Fang FC. Evaluation of tcdB real-time PCR in a three-step diagnostic algorithm for detection of toxigenic Clostridium difficile. J Clin Microbiol.2010;48(1):124-30. doi: 10.1128/ JCM.00734-09.

96. Sloan LM, Duresko BJ, Gustafson DR, Rosenblatt JE. Comparison of real-time PCR for detection of the tcdC gene with four toxin immunoassays and culture in diagnosis of Clostridium difficile infection. J Clin Microbiol. 2008;46(6):1996-2001.

97. Stamper PD, Alcabasa R, Aird D, Babiker W, Wehrlin J, Ikpeama I, et al. Comparison of a commercial real-time PCR assay for tcdB detection to a cell culture cytotoxicity assay and toxigenic culture for direct detection of toxin-producing Clostridium difficile in clinical samples. J Clin Microbiol. 2009;47(2):373-8.

98. van den Berg RJ, Bruijnesteijn van Coppenraet LS, Gerritsen HJ, Endtz HP, van der Vorm ER, Kuijper EJ. Prospective multicenter evaluation of a new immunoassay and real-time PCR for rapid diagnosis of Clostridium difficile-associated diarrhea in hospitalized patients. J Clin Microbiol. 2005;43(10):5338-40.

99. Boyanton BL, Jr., Sural P, Loomis CR, Pesta C, Gonzalez-Krellwitz L, Robinson-Dunn $B$, et al. Loop-mediated isothermal amplification compared to real-time PCR and enzyme immunoassay for toxigenic Clostridium difficile detection. J Clin Microbiol.2012;50(3):640-5. doi: 10.1128/JCM.01014-11.

100. Doing KM, Hintz MS. Prospective evaluation of the Meridian Illumigene loop-mediated amplification assay and the Gen Probe ProGastro Cd polymerase chain reaction assay for the direct detection of toxigenic Clostridium difficile from fecal samples. Diagn Microbiol Infect Dis.2012;72(1):8-13. doi: 10.1016/j.diagmicrobio.2011.09.008.

101. Ylisiurua P, Koskela M, Vainio O, Tuokko H. Comparison of antigen and two molecular methods for the detection of Clostridium difficile toxins. Scand J Infect Dis. 2013;45(1):19-25. doi: 10.3109/00365548.2012.708780.

102. Lalande V, Barrault L, Wadel S, Eckert C, Petit JC, Barbut F. Evaluation of a loop-mediated isothermal amplification assay for diagnosis of Clostridium difficile infections. J Clin Microbiol.2011;49(7):2714-6. doi: 10.1128/JCM.01835-10.

103. Pancholi P, Kelly C, Raczkowski M, Balada-Llasat JM. Detection of toxigenic Clostridium difficile: comparison of the cell culture neutralization, Xpert C. difficile, Xpert C. difficile/Epi, and Illumigene C. difficile assays. J Clin Microbiol. 2012;50(4):1331-5. doi: 10.1128/ JCM.06597-11

104. Tenover FC, Baron EJ, Peterson LR, Persing DH. Laboratory diagnosis of Clostridium difficile infection can molecular amplification methods move us out of uncertainty? J Mol Diagn. 2011;13(6):57382. doi: 10.1016/j.jmoldx.2011.06.001

105. O'Horo JC, Jones A, Sternke M, Harper C, Safdar N. Molecular techniques for diagnosis of Clostridium difficile infection: systematic review and meta-analysis. Mayo Clin Proc. 2012;87(7):643-51. DOI: 10.1016/j.mayocp.2012.02.024

106. Bouza $E$, Pelaez $T$, Alonso $R$, Catalan P, Munoz P, Creixems MR. "Second-look" cytotoxicity: an evaluation of culture plus cytotoxin assay of Clostridium difficile isolates in the laboratory diagnosis of CDAD. J Hosp Infect. 2001;48(3):233-7. DOI: 10.1053/ jhin.2001.1000

107. Fang FC, Gerding DN, Peterson LR. Diagnosis of Clostridium difficile colitis. Ann Intern Med. 1996;125(6):515; author reply 6.

108. Peterson LR, Kelly PJ. The role of the clinical microbiology labora- 
tory in the management of Clostridium difficile-associated diarrhea. Infect Dis Clin North Am. 1993;7(2):277-93.

109. Humphries RM, Uslan DZ, Rubin Z. Performance of Clostridium difficile toxin enzyme immunoassay and nucleic acid amplification tests stratified by patient disease severity. J Clin Microbiol. 2013;51(3):869-73. DOI: 10.1128/JCM.02970-12

110. Gilligan PH. Is a two-step glutamate dehyrogenase antigen-cytotoxicity neutralization assay algorithm superior to the premier toxin $A$ and $B$ enzyme immunoassay for laboratory detection of Clostridium difficile? J Clin Microbiol. 2008;46(4):1523-5.

111. Swindells J, Brenwald N, Reading N, Oppenheim B. Evaluation of diagnostic tests for Clostridium difficile infection. J Clin Microbiol. 2010;48(2):606-8. doi: 10.1128/JCM.01579-09

112. Doing KM, Hintz MS, Keefe $C$, Horne $S$, LeVasseur $S$, Kulikowski ML. Reevaluation of the Premier Clostridium difficile toxin A and B immunoassay with comparison to glutamate dehydrogenase common antigen testing evaluating Bartels cytotoxin and Prodesse ProGastro Cd polymerase chain reaction as confirmatory procedures. Diagn Microbiol Infect Dis. 2010;66(2):129-34. doi: 10.1016/j. diagmicrobio.2009.09.001.

113. Quinn CD, Sefers SE, Babiker W, He Y, Alcabasa R, Stratton CW, et al. C. Diff Quik Chek complete enzyme immunoassay provides a reliable first-line method for detection of Clostridium difficile in stool specimens. J Clin Microbiol. 2010; 48(2):603-5. doi: 10.1128/ JCM.01614-09

114. Reller ME, Lema CA, Perl TM, Cai M, Ross TL, Speck KA, et al. Yield of stool culture with isolate toxin testing versus a two-step algorithm including stool toxin testing for detection of toxigenic Clostridium difficile. J Clin Microbiol. 2007;45(11):3601-5.

115. Selvaraju SB, Gripka M, Estes K, Nguyen A, Jackson MA, Selvarangan R. Detection of toxigenic Clostridium difficile in pediatric stool samples: an evaluation of Quik Check Complete Antigen assay, BD GeneOhm Cdiff PCR, and ProGastro Cd PCR assays. Diagn Microbiol Infect Dis.71(3):224-9.

116. Wilcox MH, Planche T, Fang FC, Gilligan P. What is the current role of algorithmic approaches for diagnosis of Clostridium difficile infection? J Clin Microbiol.2010;48(12):4347-53. doi: 10.1128/ JCM.02028-10.

117. Shetty N, Wren MW, Coen PG. The role of glutamate dehydrogenase for the detection of Clostridium difficile in faecal samples: a meta-analysis. J Hosp Infect.2011;77(1):1-6. doi: 10.1016/j. jhin.2010.07.024

118. Reigadas E, Alcala L, Marin M, Martin A, Iglesias C, Bouza E. Role of binary toxin in the outcome of Clostridium difficile infection in a non-027 ribotype setting. Epidemiol Infect. 2016;144(2):268-73. DOI: 10.1017/S095026881500148X

119. Bouza E, Alcala L, Marin M, Valerio M, Reigadas E, Munoz $P$, et al. An outbreak of Clostridium difficile PCR ribotype 027 in Spain: risk factors for recurrence and a novel treatment strategy. Eur J Clin Microbiol Infect Dis. 2017;36(10):1777-86. D0I: 10.1007/s10096017-2991-y

120. Johnson AP. Drug evaluation: OPT-80, a narrow-spectrum macrocyclic antibiotic. Curr Opin Investig Drugs. 2007;8(2):168-73.
121. Pelaez T, Alcala L, Alonso R, Rodriguez-Creixems M, Garcia-Lechuz $J M$, Bouza E. Reassessment of Clostridium difficile susceptibility to metronidazole and vancomycin. Antimicrob Agents Chemother. 2002;46(6):1647-50.

122. Pelaez T, Cercenado E, Alcala L, Marin M, Martin-Lopez A, Martinez-Alarcon J, et al. Metronidazole resistance in Clostridium difficile is heterogeneous. J Clin Microbiol. 2008;46(9):3028-32. DOI: 10.1128/JCM.00524-08

123. Bishara J, Bloch Y, Garty M, Behor J, Samra Z. Antimicrobial resistance of Clostridium difficile isolates in a tertiary medical center, Israel. Diagn Microbiol Infect Dis. 2006;54(2):141-4. DOI: 10.1016/j. diagmicrobio.2005.09.008

124. Martin H, Willey B, Low DE, Staempfli HR, McGeer A, Boerlin P, et al. Characterization of Clostridium difficile strains isolated from patients in Ontario, Canada, from 2004 to 2006. J Clin Microbiol. 2008;46(9):2999-3004. DOI: 10.1128/JCM.02437-07

125. Huang $H$, Weintraub $A$, Fang $H$, Wu S, Zhang $Y$, Nord CE. Antimicrobial susceptibility and heteroresistance in Chinese Clostridium difficile strains. Anaerobe. 2010;16(6):633-5. DOI: 10.1016/j.anaerobe.2010.09.002

126. CLSI. Methods for antimicrobial susceptibility testing of anaerobic bacteria. 2007.

127. Teasley DG, Gerding DN, Olson MM, Peterson LR, Gebhard RL, Schwartz MJ, et al. Prospective randomised trial of metronidazole versus vancomycin for Clostridium-difficile-associated diarrhoea and colitis. Lancet. 1983;2(8358):1043-6.

128. Wenisch C, Parschalk B, Hasenhundl M, Hirschl AM, Graninger W. Comparison of vancomycin, teicoplanin, metronidazole, and fusidic acid for the treatment of Clostridium difficile-associated diarrhea. Clin Infect Dis. 1996;22(5):813-8.

129. Bartlett JG. New drugs for Clostridium difficile infection. Clin Infect Dis. 2006;43(4):428-31. DOI: 10.1086/506387

130. Zar FA, Bakkanagari SR, Moorthi KM, Davis MB. A comparison of vancomycin and metronidazole for the treatment of Clostridium difficile-associated diarrhea, stratified by disease severity. Clin Infect Dis. 2007;45(3):302-7. DOI: 10.1086/519265

131. Louie TJ, Peppe J, Watt CK, Johnson D, Mohammed R, Dow G, et al. Tolevamer, a novel nonantibiotic polymer, compared with vancomycin in the treatment of mild to moderately severe Clostridium difficile-associated diarrhea. Clin Infect Dis. 2006;43(4):411-20. DOI: 10.1086/506349

132. Kim KH, Fekety $R$, Batts DH, Brown D, Cudmore $M$, Silva J, Jr., et al. Isolation of Clostridium difficile from the environment and contacts of patients with antibiotic-associated colitis. J Infect Dis. 1981;143(1):42-50.

133. Fekety R, Kim KH, Brown D, Batts DH, Cudmore M, Silva J, Jr. Epidemiology of antibiotic-associated colitis; isolation of Clostridium difficile from the hospital environment. Am J Med. 1981;70(4):906-8.

134. McFarland LV, Elmer GW, Surawicz CM. Breaking the cycle: treatment strategies for 163 cases of recurrent Clostridium difficile disease. Am J Gastroenterol. 2002;97(7):1769-75. DOI: 10.1111/j.1572-0241.2002.05839.x

135. www.cdc.gov. 
136. Johnson S, Gerding DN, Olson MM, Weiler MD, Hughes RA, Clabots $\mathrm{CR}$, et al. Prospective, controlled study of vinyl glove use to interrupt Clostridium difficile nosocomial transmission. Am J Med. 1990;88(2):137-40.

137. Boyce JM, Pittet D. Guideline for Hand Hygiene in Health-Care Settings. Recommendations of the Healthcare Infection Control Practices Advisory Committee and the HICPAC/SHEA/APIC/IDSA Hand Hygiene Task Force. Society for Healthcare Epidemiology of America/Association for Professionals in Infection Control/Infectious Diseases Society of America. MMWR Recomm Rep. 2002;51(RR16):1-45, quiz CE1-4.

138. Garner JS. Guideline for isolation precautions in hospitals. The Hospital Infection Control Practices Advisory Committee. Infect Control Hosp Epidemiol. 1996;17(1):53-80.

139. Bolton RP, Culshaw MA. Faecal metronidazole concentrations during oral and intravenous therapy for antibiotic associated colitis due to Clostridium difficile. Gut. 1986;27(10):1169-72. DOI: 10.1136/gut.27.10.1169

140. The European Committee on Antimicrobial Susceptibility Testing. Breakpoint tables for interpretation of MICs and zone diameters. www.eucast.org. 2015.

141. Sethi AK, Al-Nassir WN, Nerandzic MM, Bobulsky GS, Donskey CJ. Persistence of skin contamination and environmental shedding of Clostridium difficile during and after treatment of $\mathrm{C}$. difficile infection. Infect Control Hosp Epidemiol. 2010;31(1):21-7. DOI: $10.1086 / 649016$

142. Sehulster L, Chinn RY. Guidelines for environmental infection control in health-care facilities. Recommendations of CDC and the Healthcare Infection Control Practices Advisory Committee (HICPAC). MMWR Recomm Rep. 2003;52(RR-10):1-42.

143. Barbut F, Petit JC. Epidemiology of Clostridium difficile-associated infections. Clin Microbiol Infect. 2001;7(8):405-10. DOI: S1198743X(14)62683-5 [pii]

144. Gerding DN, Johnson S, Peterson LR, Mulligan ME, Silva J, Jr. Clostridium difficile-associated diarrhea and colitis. Infect Control Hosp Epidemiol. 1995;16(8):459-77.

145. Davey P, Brown E, Fenelon L, Finch R, Gould I, Hartman G, et al. Interventions to improve antibiotic prescribing practices for hospital inpatients. Cochrane Database Syst Rev. 2005(4):CD003543. D0I: 10.1002/14651858.CD003543.pub2

146. Simor AE, Bradley SF, Strausbaugh $\amalg$, Crossley K, Nicolle LE. Clostridium difficile in long-term-care facilities for the elderly. Infect Control Hosp Epidemiol. 2002;23(11):696-703. DOI: 10.1086/501997

147. Yassin SF, Young-Fadok TM, Zein NN, Pardi DS. Clostridium difficileassociated diarrhea and colitis. Mayo Clin Proc. 2001;76(7):725-30. DOI: 10.4065/76.7.725

148. Hurley BW, Nguyen CC. The spectrum of pseudomembranous enterocolitis and antibiotic-associated diarrhea. Arch Intern Med. 2002;162(19):2177-84.

149. Aslam S, Hamill RJ, Musher DM. Treatment of Clostridium difficileassociated disease: old therapies and new strategies. Lancet Infect Dis. 2005;5(9):549-57. DOI: 10.1016/S1473-3099(05)70215-2
150. Bouza E, Munoz P, Alonso R. Clinical manifestations, treatment and control of infections caused by Clostridium difficile. Clin Microbiol Infect. 2005;11 Suppl 4:57-64.

151. Shivashankar R, Khanna $S$, Kammer PP, Harmsen WS, Zinsmeister AR, Baddour LM, et al. Clinical factors associated with development of severe-complicated Clostridium difficile infection. Clin Gastroenterol Hepatol. 2013;11(11):1466-71. DOI: 10.1016/j. cgh.2013.04.050

152. Howell MD, Novack V, Grgurich P, Soulliard D, Novack L, Pencina M, et al. latrogenic gastric acid suppression and the risk of nosocomial Clostridium difficile infection. Arch Intern Med. 2010;170(9):78490. DOI: 10.1001/archinternmed.2010.89

153. Janarthanan S, Ditah I, Adler DG, Ehrinpreis MN. Clostridium difficile-associated diarrhea and proton pump inhibitor therapy: a metaanalysis. Am J Gastroenterol. 2012;107(7):1001-10. DOI: 10.1038/ ajg.2012.179

154. Johnson S, Louie TJ, Gerding DN, Cornely OA, Chasan-Taber S, Fitts D, et al. Vancomycin, metronidazole, or tolevamer for Clostridium difficile infection: results from two multinational, randomized, controlled trials. Clin Infect Dis. 2014;59(3):345-54. DOI: 10.1093/ cid/ciu313

155. Musher DM, Aslam S, Logan N, Nallacheru S, Bhaila I, Borchert F, et al. Relatively poor outcome after treatment of Clostridium difficile colitis with metronidazole. Clin Infect Dis. 2005;40(11):1586-90. DOI: $10.1086 / 430311$

156. Johnson AP, Wilcox MH. Fidaxomicin: a new option for the treatment of Clostridium difficile infection. J Antimicrob Chemother. 2012;67(12):2788-92. D0I: 10.1093/jac/dks302

157. Mullane KM, Miller MA, Weiss K, Lentnek A, Golan Y, Sears PS, et al. Efficacy of fidaxomicin versus vancomycin as therapy for Clostridium difficile infection in individuals taking concomitant antibiotics for other concurrent infections. Clin Infect Dis. 2011;53(5):4407. DOI: $10.1093 / \mathrm{cid} / \mathrm{cir} 404$

158. Rubio-Terres C, Cobo Reinoso J, Grau Cerrato S, Mensa Pueyo J,

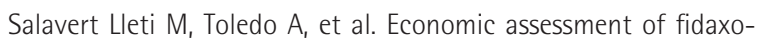
micin for the treatment of Clostridium difficile infection (CDI) in special populations (patients with cancer, concomitant antibiotic treatment or renal impairment) in Spain. Eur J Clin Microbiol Infect Dis. 2015;34(11):2213-23. DOI: 10.1007/s10096-015-2472-0

159. Cornely OA, Miller MA, Fantin B, Mullane $K$, Kean $Y$, Gorbach S. Resolution of Clostridium difficile-Associated Diarrhea in Patients With Cancer Treated With Fidaxomicin or Vancomycin. J Clin Oncol. 2013;31(19):2493-9. doi: 10.1200/JC0.2012.45.5899.

160. Nathwani D, Cornely OA, Van Engen AK, Odufowora-Sita O, Retsa P, Odeyemi IA. Cost-effectiveness analysis of fidaxomicin versus vancomycin in Clostridium difficile infection. J Antimicrob Chemother. 2014;69(11):2901-12. DOI: 10.1093/jac/dku257

161. Cornely OA, Nathwani D, Ivanescu C, Odufowora-Sita O, Retsa $P$, Odeyemi IA. Clinical efficacy of fidaxomicin compared with vancomycin and metronidazole in Clostridium difficile infections: a meta-analysis and indirect treatment comparison. J Antimicrob Chemother. 2014;69(11):2892-900. D0I: 10.1093/ jac/dku261 
162. Loo VG. Association of Medical Microbiology and Infectious Disease Canada treatment practice guidelines for Clostridium difficile infection. Official Journal of the Association of Medical Microbiology and Infectious Disease Canada. 2018;3.2:71-92. DOI: 10.3138/jammi.2018.02.13

163. Menees SB, Maneerattannaporn M, Kim HM, Chey WD. The efficacy and safety of rifaximin for the irritable bowel syndrome: a systematic review and meta-analysis. Am J Gastroenterol. 2012;107(1):2835; quiz 6. DOI: 10.1038/ajg.2011.355

164. Garey KW, Ghantoji SS, Shah DN, Habib M, Arora V, Jiang ZD, et al. A randomized, double-blind, placebo-controlled pilot study to assess the ability of rifaximin to prevent recurrent diarrhoea in patients with Clostridium difficile infection. J Antimicrob Chemother. 2011;66(12):2850-5. DOI: 10.1093/jac/dkr377

165. Rubin DT, Sohi S, Glathar M, Thomas T, Yadron N, Surma BL. Rifaximin Is Effective for the Treatment of Clostridium difficile-Associated Diarrhea: Results of an Open-Label Pilot Study. Gastroenterol Res Pract. 2011;2011:106978. DOI: 10.1155/2011/106978

166. Musher DM, Logan N, Bressler AM, Johnson DP, Rossignol JF. Nitazoxanide versus vancomycin in Clostridium difficile infection: a randomized, double-blind study. Clin Infect Dis. 2009;48(4):e41-6. DOI: $10.1086 / 596552$

167. Musher DM, Logan N, Hamill RJ, Dupont HL, Lentnek A, Gupta A, et al. Nitazoxanide for the treatment of Clostridium difficile colitis. Clin Infect Dis. 2006;43(4):421-7. DOI: 10.1086/506351

168. Musher DM, Logan N, Mehendiratta V, Melgarejo NA, Garud S, Hamill RJ. Clostridium difficile colitis that fails conventional metronidazole therapy: response to nitazoxanide. J Antimicrob Chemother. 2007;59(4):705-10. DOI: 10.1093/jac/dkl553

169. Noren $T$, Wullt M, Akerlund $T$, Back $E$, Odenholt I, Burman LG. Frequent emergence of resistance in Clostridium difficile during treatment of C. difficile-associated diarrhea with fusidic acid. Antimicrob Agents Chemother. 2006;50(9):3028-32. DOI: 10.1128/ AAC.00019-06

170. Larson KC, Belliveau PP, Spooner LM. Tigecycline for the treatment of severe Clostridium difficile infection. Ann Pharmacother. 2011;45(7-8):1005-10. DOI: 10.1345/aph.10080

171. Herpers BL, Vlaminckx B, Burkhardt 0 , Blom H, Biemond-Moeniralam HS, Hornef $M$, et al. Intravenous tigecycline as adjunctive or alternative therapy for severe refractory Clostridium difficile infection. Clin Infect Dis. 2009;48(12):1732-5. DOI: 10.1086/599224

172. de Lalla F, Nicolin R, Rinaldi E, Scarpellini P, Rigoli R, Manfrin $V_{1}$ et al. Prospective study of oral teicoplanin versus oral vancomycin for therapy of pseudomembranous colitis and Clostridium difficile-associated diarrhea. Antimicrob Agents Chemother. 1992;36(10):2192-6. 245474

173. Carman RJ, Boone JH, Grover H, Wickham KN, Chen L. In vivo selection of rifamycin-resistant Clostridium difficile during rifaximin therapy. Antimicrob Agents Chemother. 2012;56(11):6019-20. D0I: 10.1128/AAC.00974-12

174. Baldoni D, Gutierrez M, Timmer W, Dingemanse J. Cadazolid, a novel antibiotic with potent activity against Clostridium difficile: safety, tolerability and pharmacokinetics in healthy subjects fo-
Ilowing single and multiple oral doses. J Antimicrob Chemother. 2014;69(3):706-14. DOI: 10.1093/jac/dkt401

175. Locher HH, Caspers $P$, Bruyere T, Schroeder S, Pfaff $P$, Knezevic $A$, et al. Investigations of the mode of action and resistance development of cadazolid, a new antibiotic for treatment of Clostridium difficile infections. Antimicrob Agents Chemother. 2014;58(2):9018. DOI: 10.1128/AAC.01831-13

176. Chilton $\mathrm{CH}$, Crowther GS, Baines SD, Todhunter SL, Freeman J, Locher $\mathrm{HH}$, et al. In vitro activity of cadazolid against clinically relevant Clostridium difficile isolates and in an in vitro gut model of C. difficile infection. J Antimicrob Chemother. 2014;69(3):697-705. DOI: $10.1093 / j a c / d k t 411$

177. Gerding DN, Cornely OA, Grill S, Kracker H, Marrast AC, Nord CE, et al. Cadazolid for the treatment of Clostridium difficile infection: results of two double-blind, placebo-controlled, non-inferiority, randomised phase 3 trials. Lancet Infect Dis. 2019;19(3):265-74. DOI: 10.1016/s1473-3099(18)30614-5

178. Vickers RJ, Tillotson G, Goldstein EJ, Citron DM, Garey KW, Wilcox MH. Ridinilazole: a novel therapy for Clostridium difficile infection. Int J Antimicrob Agents. 2016;48(2):137-43. DOI: 10.1016/j.ijantimicag.2016.04.026

179. Vickers RJ, Tillotson GS, Nathan R, Hazan S, Pullman J, Lucasti C, et al. Efficacy and safety of ridinilazole compared with vancomycin for the treatment of Clostridium difficile infection: a phase 2, randomised, double-blind, active-controlled, non-inferiority study. Lancet Infect Dis. 2017;17(7):735-44. DOI: 10.1016/S14733099(17)30235-9

180. US Governement. https://clinicaltrials.gov/ct2/results?cond=Ridi nilazolectterm $=\varepsilon t$ type $=\varepsilon t r s \mid t=\varepsilon t a g e \_v=\varepsilon t g n d r=\varepsilon t i n t r=\varepsilon t$ titles $=\varepsilon t o$

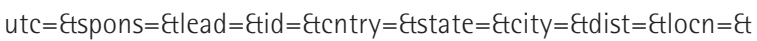
strd_s=Etstrd_e=Etprcd_s=Etprcd_e=Etsfpd_s=etsfpd_e=Etlupd_ $\mathrm{s}=$ Ctlupd_e=Ctsort=. Assessed January first 2020.

181. Markham A. Bezlotoxumab: First Global Approval. Drugs. 2016; 76(18):1793-8. DOI: 10.1007/s40265-016-0673-1

182. Abougergi MS, Broor A, Cui W, Jaar BG. Intravenous immunoglobulin for the treatment of severe Clostridium difficile colitis: an observational study and review of the literature. J Hosp Med. 2010;5(1):E1-9. DOI: 10.1002/jhm.542

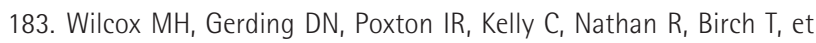
al. Bezlotoxumab for Prevention of Recurrent Clostridium difficile Infection. N Engl J Med. 2017;376(4):305-17. DOI: 10.1056/NEJMoa1602615

184. Agencia Española de Medicamentos y Productos Sanitarios. Informe de Posicionamiento Terapéutico de bezlotoxumab (Zinplava ${ }^{\circledR}$ ) en la prevención de la recurrencia de la infección por Clostridium difficile en adultos con alto riesgo de recurrencia. IPT, 31. 2018.

185. Gerding DN, Kelly CP, Rahav G, Lee C, Dubberke ER, Kumar PN, et al. Bezlotoxumab for Prevention of Recurrent Clostridium difficile Infection in Patients at Increased Risk for Recurrence. Clin Infect Dis. 2018;67(5):649-56. D0I: 10.1093/cid/ciy171

186. Kyne L, Warny M, Qamar A, Kelly CP. Association between antibody response to toxin $\mathrm{A}$ and protection against recurrent Clostridium difficile diarrhoea. Lancet. 2001;357(9251):189-93. DOI: 10.1016/ 


\section{s0140-6736(00)03592-3}

187. Kim YG, Graham DY, Jang BI. Proton pump inhibitor use and recurrent Clostridium difficile-associated disease: a case-control analysis matched by propensity score. J Clin Gastroenterol. 2012;46(5):397-400. DOI: 10.1097/MCG.0b013e3182431d78

188. Linsky A, Gupta K, Lawler EV, Fonda JR, Hermos JA. Proton pump inhibitors and risk for recurrent Clostridium difficile infection. Arch Intern Med. 2010;170(9):772-8. DOI: 10.1001/archinternmed.2010.73

189. Nair S, Yadav D, Corpuz M, Pitchumoni CS. Clostridium difficile colitis: factors influencing treatment failure and relapse--a prospective evaluation. Am J Gastroenterol. 1998;93(10):1873-6. DOI: 10.1111/j.1572-0241.1998.00541.x

190. Daniels LM, Kufel WD. Clinical review of Clostridium difficile infection: an update on treatment and prevention. Expert opinion on pharmacotherapy. 2018;19(16):1759-69. DOI: 10.1080/14656566.2018.1524872

191. Hu MY, Katchar K, Kyne L, Maroo S, Tummala S, Dreisbach V, et al. Prospective derivation and validation of a clinical prediction rule for recurrent Clostridium difficile infection. Gastroenterology. 2009;136(4):1206-14. DOI: 10.1053/j.gastro.2008.12.038

192. Miller MA, Louie T, Mullane K, Weiss K, Lentnek A, Golan Y, et al. Derivation and validation of a simple clinical bedside score (ATLAS) for Clostridium difficile infection which predicts response to therapy. BMC Infect Dis. 2013;13:148. DOI: 10.1186/1471-2334-13-148

193. D'Agostino RB, Sr., Collins SH, Pencina KM, Kean Y, Gorbach S. Risk estimation for recurrent Clostridium difficile infection based on clinical factors. Clin Infect Dis. 2014;58(10):1386-93. DOI: 10.1093/ $\mathrm{cid} / \mathrm{ciu} 107$

194. Zilberberg MD, Reske K, Olsen M, Yan Y, Dubberke ER. Development and validation of a recurrent Clostridium difficile risk-prediction model. J Hosp Med. 2014;9(7):418-23. DOI: 10.1002/jhm.2189

195. Viswesh V, Hincapie AL, Yu M, Khatchatourian L, Nowak MA. Development of a bedside scoring system for predicting a first recurrence of Clostridium difficile-associated diarrhea. Am J Health Syst Pharm. 2017;74(7):474-82. DOI: 10.2146/ajhp160186

196. Escobar GJ, Baker JM, Kipnis P, Greene JD, Mast TC, Gupta SB, et al. Prediction of Recurrent Clostridium difficile Infection Using Comprehensive Electronic Medical Records in an Integrated Healthcare Delivery System. Infect Control Hosp Epidemiol. 2017;38(10):1196203. DOI: $10.1017 /$ ice.2017.176

197. Reveles KR, Mortensen EM, Koeller JM, Lawson KA, Pugh MJV, Rumbellow SA, et al. Derivation and Validation of a Clostridium difficile Infection Recurrence Prediction Rule in a National Cohort of Veterans. Pharmacotherapy. 2018;38(3):349-56. DOI: 10.1002/ phar.2088

198. Cobo J, Merino E, Martinez C, Cozar-Llisto A, Shaw E, Marrodan T, et al. Prediction of recurrent Clostridium difficile infection at the bedside: the GEIH-CDI score. Int J Antimicrob Agents. 2018;51(3):3938. DOI: 10.1016/j.ijantimicag.2017.09.010

199. Reigadas E, Alcala L, Valerio M, Marin M, Martin A, Bouza E. Toxin B PCR cycle threshold as a predictor of poor outcome of Clostridium difficile infection: a derivation and validation cohort study. J Anti- microb Chemother. 2016;71(5):1380-5. D0I: 10.1093/jac/dkv497

200. Davies KA, Planche T, Wilcox MH. The predictive value of quantitative nucleic acid amplification detection of Clostridium difficile toxin gene for faecal sample toxin status and patient outcome. PLoS One. 2018;13(12):e0205941. DOI: 10.1371/journal.pone.0205941

201. Schwenk HT, Bio LL, Kruger JF, Banaei N. Clinical Impact of Clostridium difficile PCR Cycle Threshold-Predicted Toxin Reporting in Pediatric Patients. J Pediatric Infect Dis Soc. 2018. DOI: 10.1093/ jpids/piy117

202. Wilmore S, Goldenberg SD. Potential of real-time PCR threshold cycle (CT) to predict presence of free toxin and clinically relevant C. difficile infection (CDI) in patients with cancer: A reply. J Infect. 2018;76(4):424-6. DOI: 10.1016/j.jinf.2018.01.001

203. Origuen J, Orellana MA, Fernandez-Ruiz $M$, Corbella $L$, San Juan $R$, Ruiz-Ruigomez M, et al. Toxin B PCR Amplification Cycle Threshold Adds Little to Clinical Variables for Predicting Outcomes in Clostridium difficile Infection: a Retrospective Cohort Study. J Clin Microbiol. 2019;57(2). DOI: 10.1128/jcm.01125-18

204. Reigadas E, Alcala L, Marin M, Martin A, Bouza E. Clinical, immunological and microbiological predictors of poor outcome in Clostridium difficile infection. Diagn Microbiol Infect Dis. 2017;88(4):3304. D0I: 10.1016/j.diagmicrobio.2017.05.005

205. McFarland LV, Surawicz CM, Rubin M, Fekety R, Elmer GW, Greenberg RN. Recurrent Clostridium difficile disease: epidemiology and clinical characteristics. Infect Control Hosp Epidemiol. 1999;20(1):43-50. DOI: 10.1086/501553

206. Bruxelle JF, Pechine S, Collignon A. Immunization Strategies Against Clostridium difficile. Adv Exp Med Biol. 2018;1050:197-225. DOI: 10.1007/978-3-319-72799-8_12

207. Juang P, Skledar SJ, Zgheib NK, Paterson DL, Vergis EN, Shannon $W D$, et al. Clinical outcomes of intravenous immune globulin in severe Clostridium difficile-associated diarrhea. Am J Infect Control. 2007;35(2):131-7. DOI: 10.1016/j.ajic.2006.06.007

208. Heidebrecht HJ, Weiss WJ, Pulse M, Lange A, Gisch K, Kliem H, et al. Treatment and Prevention of Recurrent Clostridium difficile Infection with Functionalized Bovine Antibody-Enriched Whey in a Hamster Primary Infection Model. Toxins (Basel). 2019;11(2). DOI: 10.3390/toxins11020098

209. Cammarota G, Masucci L, laniro G, Bibbo S, Dinoi G, Costamagna G, et al. Randomised clinical trial: faecal microbiota transplantation by colonoscopy vs. vancomycin for the treatment of recurrent Clostridium difficile infection. Aliment Pharmacol Ther. 2015;41(9):83543. DOI: 10.1111/apt.13144

210. Kelly CR, Khoruts A, Staley C, Sadowsky MJ, Abd M, Alani M, et al. Effect of Fecal Microbiota Transplantation on Recurrence in Multiply Recurrent Clostridium difficile Infection: A Randomized Trial. Ann Intern Med. 2016;165(9):609-16. DOI: 10.7326/M16-0271

211. Cammarota $G$, laniro $G$, Tilg $H$, Rajilic-Stojanovic $M$, Kump P, Satokari $R$, et al. European consensus conference on faecal microbiota transplantation in clinical practice. Gut. 2017;66(4):569-80. DOI: 10.1136/gutjnl-2016-313017

212. Mullish BH, Quraishi MN, Segal JP, McCune VL, Baxter M, Marsden $\mathrm{GL}$, et al. The use of faecal microbiota transplant as treatment 
for recurrent or refractory Clostridium difficile infection and other potential indications: joint British Society of Gastroenterology (BSG) and Healthcare Infection Society (HIS) guidelines. Gut. 2018;67(11):1920-41. DOI: 10.1136/gutjnl-2018-316818

213. Sokol H, Galperine T, Kapel N, Bourlioux P, Seksik P, Barbut F, et al. Faecal microbiota transplantation in recurrent Clostridium difficile infection: Recommendations from the French Group of Faecal microbiota Transplantation. Dig Liver Dis. 2016;48(3):242-7. D0I: 10.1016/j.dld.2015.08.017

214. Eliadou E, Day AS, Thompson-Fawcett MW, Gearry RB, Rowbotham DS, Walmsley R, et al. New Zealand Society of Gastroenterology Guidelines for the Management of Refractory Ulcerative Colitis. N Z Med J. 2015;128(1423):63-76.

215. Paramsothy S, Borody TJ, Lin E, Finlayson S, Walsh AJ, Samuel $D$, et al. Donor Recruitment for Fecal Microbiota Transplantation. Inflamm Bowel Dis. 2015;21(7):1600-6. D0I: 10.1097/ MIB.0000000000000405

216. Jiang ZD, Ajami NJ, Petrosino JF, Jun G, Hanis CL, Shah M, et al. Randomised clinical trial: faecal microbiota transplantation for recurrent Clostridum difficile infection - fresh, or frozen, or lyophilised microbiota from a small pool of healthy donors delivered by colonoscopy. Aliment Pharmacol Ther. 2017;45(7):899-908. DOI: 10.1111/apt.13969

217. Kao D, Roach B, Silva M, Beck P, Rioux K, Kaplan GG, et al. Effect of Oral Capsule- vs Colonoscopy-Delivered Fecal Microbiota Transplantation on Recurrent Clostridium difficile Infection: A Randomized Clinical Trial. JAMA. 2017;318(20):1985-93. DOI: 10.1001/ jama.2017.17077

218. Youngster I, Russell GH, Pindar C, Ziv-Baran T, Sauk J, Hohmann EL. Oral, capsulized, frozen fecal microbiota transplantation for relapsing Clostridium difficile infection. Jama. 2014;312(17):1772-8. DOI: 10.1001/jama.2014.13875

219. Tang G, Yin W, Liu W. Is frozen fecal microbiota transplantation as effective as fresh fecal microbiota transplantation in patients with recurrent or refractory Clostridium difficile infection: A meta-analysis? Diagn Microbiol Infect Dis. 2017;88(4):322-9. DOI: 10.1016/j.diagmicrobio.2017.05.007

220. McCune VL, Struthers JK, Hawkey PM. Faecal transplantation for the treatment of Clostridium difficile infection: a review. Int J Antimicrob Agents. 2014;43(3):201-6. DOI: 10.1016/j.ijantimicag.2013.10.009

221. Orenstein R, Dubberke E, Hardi R, Ray A, Mullane K, Pardi DS, et al. Safety and Durability of RBX2660 (Microbiota Suspension) for Recurrent Clostridium difficile Infection: Results of the PUNCH CD Study. Clin Infect Dis. 2016;62(5):596-602. D0I: 10.1093/cid/civ938

222. Quraishi MN, Widlak M, Bhala $N$, Moore $D$, Price $M$, Sharma $N$, et al. Systematic review with meta-analysis: the efficacy of faecal microbiota transplantation for the treatment of recurrent and refractory Clostridium difficile infection. Aliment Pharmacol Ther. 2017;46(5):479-93. DOI: 10.1111/apt.14201

223. Hota SS, Sales V, Tomlinson G, Salpeter MJ, McGeer A, Coburn B, et al. Oral Vancomycin Followed by Fecal Transplantation Versus Tapering Oral Vancomycin Treatment for Recurrent Clostridium difficile
Infection: An Open-Label, Randomized Controlled Trial. Clin Infect Dis. 2017;64(3):265-71. DOI: 10.1093/cid/ciw731

224. Kassam Z, Lee $C H$, Yuan $Y$, Hunt RH. Fecal microbiota transplantation for Clostridium difficile infection: systematic review and meta-analysis. Am J Gastroenterol. 2013;108(4):500-8. DOI: 10.1038/ ajg.2013.59

225. van Nood E, Vrieze A, Nieuwdorp M, Fuentes S, Zoetendal EG, de Vos WM, et al. Duodenal infusion of donor feces for recurrent Clostridium difficile. N Engl J Med. 2013;368(5):407-15. DOI: 10.1056/ NEJMoa1205037

226. Kuijper EJ, Allegretii J, Hawkey P, Sokol H, Goldenberg S, laniro G, et al. A necessary discussion after transmission of multidrug-resistant organisms through faecal microbiota transplantations. Lancet Infect Dis. 2019;19(11):1161-2. DOI: 10.1016/s1473-3099(19)30545-6

227. Defilipp Z, Bloom PP, Torres Soto M, Mansour MK, Sater MRA, Huntley MH, et al. Drug-Resistant E. coli Bacteremia Transmitted by Fecal Microbiota Transplant. N Engl J Med. 2019;381(21):204350. DOI: 10.1056/NEJMoa1910437

228. Bhangu A, Nepogodiev D, Gupta A, Torrance A, Singh P. Systematic review and meta-analysis of outcomes following emergency surgery for Clostridium difficile colitis. Br J Surg. 2012;99(11):150113. DOI: $10.1002 /$ bjs.8868

229. Neal MD, Alverdy JC, Hall DE, Simmons RL, Zuckerbraun BS. Diverting loop ileostomy and colonic lavage: an alternative to total abdominal colectomy for the treatment of severe, complicated Clostridium difficile associated disease. Ann Surg. 2011;254(3):423-7; discussion 7-9. DOI: 10.1097/SLA.0b013e31822ade48

230. Olivas AD, Umanskiy K, Zuckerbraun B, Alverdy JC. Avoiding colectomy during surgical management of fulminant Clostridium difficile colitis. Surg Infect (Larchmt). 2010;11(3):299-305. DOI: 10.1089/ sur.2010.026

231. Ferrada $P$, Callcut $R$, Zielinski MD, Bruns B, Yeh DD, Zakrison TL, et al. Loop ileostomy versus total colectomy as surgical treatment for Clostridium difficile-associated disease: An Eastern Association for the Surgery of Trauma multicenter trial. J Trauma Acute Care Surg. 2017;83(1):36-40. DOI: 10.1097/TA.0000000000001498

232. McKechnie T, Lee Y, Springer JE, Doumouras AG, Hong D, Eskicioglu C. Diverting loop ileostomy with colonic lavage as an alternative to colectomy for fulminant Clostridioides difficile: a systematic review and meta-analysis. Int J Colorectal Dis. 2019. D0I: 10.1007/s00384019-03447-3

233. Henderson M, Bragg A, Fahim G, Shah M, Hermes-DeSantis ER. A Review of the Safety and Efficacy of Vaccines as Prophylaxis for Clostridium difficile Infections. Vaccines (Basel). 2017;5(3). DOI:10.3390/vaccines5030025 vaccines5030025 [pii]

234. US Government. https://clinicaltrials.gov/ct2/results?cond=Diffici

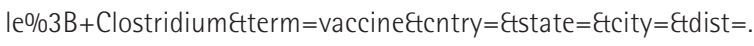
Assessed January first 2020.

235. Bezay N, Ayad A, Dubischar K, Firbas C, Hochreiter R, Kiermayr S, et al. Safety, immunogenicity and dose response of VLA84, a new vaccine candidate against Clostridium difficile, in healthy volunteers. Vaccine. 2016;34(23):2585-92. DOI: 10.1016/j.vaccine.2016.03.098

236. Greenberg RN, Marbury TC, Foglia G, Warny M. Phase I dose finding 
E. Bouza, et al.

Recommendations for the diagnosis and treatment of Clostridioides difficile infection: An official clinical practice guideline of the Spanish Society of Chemotherapy (SEQ), Spanish Society of Internal Medicine (SEMI) and the working group of Postoperative Infection of the Spanish Society of Anesthesia and Reanimation (SEDAR)

studies of an adjuvanted Clostridium difficile toxoid vaccine. Vaccine. 2012;30(13):2245-9. DOI: 10.1016/j.vaccine.2012.01.065

237. McFarland LV. Systematic review and meta-analysis of Saccharomyces boulardii in adult patients. World J Gastroenterol. 2010;16(18):2202-22. 2868213

238. Johnson S, Maziade PJ, McFarland LV, Trick W, Donskey C, Currie B, et al. Is primary prevention of Clostridium difficile infection possible with specific probiotics? Int J Infect Dis. 2012;16(11):e786-92. DOI: 10.1016/j.ijid.2012.06.005

239. Goldenberg JZ, Ma SS, Saxton JD, Martzen MR, Vandvik PO,

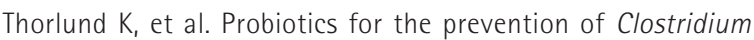
difficile-associated diarrhea in adults and children. Cochrane Database Syst Rev. 2013(5):CD006095. D0I: 10.1002/14651858. CD006095.pub3

240. Allen SJ, Wareham K, Wang D, Bradley $C_{1}$ Hutchings $H_{1}$ Harris W, et al. Lactobacilli and bifidobacteria in the prevention of antibioticassociated diarrhoea and Clostridium difficile diarrhoea in older inpatients (PLACIDE): a randomised, double-blind, placebo-controlled, multicentre trial. Lancet. 2013;382(9900):1249-57. DOI: 10.1016/S0140-6736(13)61218-0

241. Appaneal HJ, Caffrey AR, Beganovic M, Avramovic S, LaPlante KL. Predictors of Clostridioides difficile recurrence across a national cohort of veterans in outpatient, acute, and long-term care settings. Am J Health Syst Pharm. 2019;76(9):581-90. DOI: 10.1093/ ajhp/zxz032

242. Rubio-Terres C, Aguado JM, Almirante B, Cobo J, Grau S, Salavert $M$, et al. Extended-pulsed fidaxomicin versus vancomycin in patients 60 years and older with Clostridium difficile infection: cost-effectiveness analysis in Spain. Eur J Clin Microbiol Infect Dis. 2019;38(6):1105-11. DOI: 10.1007/s10096-019-03503-4

243. Johnson S. Recurrent Clostridium difficile infection: a review of risk factors, treatments, and outcomes. J Infect. 2009;58(6):403-10. DOI: 10.1016/j.jinf.2009.03.010

244. Khanna S, Pardi DS. Clostridium difficile infection: new insights into management. Mayo Clin Proc. 2012;87(11):1106-17. DOI: 10.1016/j.mayocp.2012.07.016

245. Sirbu BD, Soriano MM, Manzo C, Lum J, Gerding DN, Johnson S. Vancomycin Taper and Pulse Regimen With Careful Follow-up for Patients With Recurrent Clostridium difficile Infection. Clin Infect Dis. 2017;65(8):1396-9. DOI: 10.1093/cid/cix529

246. Guery B, Menichetti F, Anttila VJ, Adomakoh N, Aguado JM, Bisnauthsing $K_{1}$ et al. Extended-pulsed fidaxomicin versus vancomycin for Clostridium difficile infection in patients 60 years and older (EXTEND): a randomised, controlled, open-label, phase 3b/4 trial. Lancet Infect Dis. 2018;18(3):296-307. DOI: 10.1016/S14733099(17)30751-X

247. Sheitoyan-Pesant C, Abou Chakra CN, Pepin J, Marcil-Heguy A, Nault V, Valiquette L. Clinical and Healthcare Burden of Multiple Recurrences of Clostridium difficile Infection. Clin Infect Dis. 2016;62(5):574-80. DOI: 10.1093/cid/civ958

248. Carignan A, Poulin S, Martin P, Labbe AC, Valiquette L, Al-Bachari $H_{\text {, }}$ et al. Efficacy of Secondary Prophylaxis With Vancomycin for Preventing Recurrent Clostridium difficile Infections. Am J Gastroen- terol. 2016;111(12):1834-40. DOI: 10.1038/ajg.2016.417

249. Knight EM, Schiller DS, Fulman MK, Rastogi R. Long-Term Efficacy of Oral Vancomycin Prophylaxis for the Prevention of Clostridium difficile Recurrence. J Pharm Pract. 2019:897190019825994. DOI: 10.1177/0897190019825994

250. Zhang $K$, Beckett $P$, Abouanaser $S$, Stankus V, Lee C, Smieja M. Prolonged oral vancomycin for secondary prophylaxis of relapsing Clostridium difficile infection. BMC Infect Dis. 2019;19(1):51. DOI: 10.1186/s12879-019-3676-1

251. Vyas. NM, C. H, Levin. TP, editors. Assessment of compliace with Clostridioides difficile prophylaxis guideline and its efficacy on secondary prophylaxis and reducing hospital-onset Clostridioides difficile infections. IDWeek; 2019; Washington, USA: Abstract 2413.

252. Zacharioudakis. I, Zervou. F, Dubrovskaya. I, Phillips. MS, editors. Oral Vancomycin Prophylaxis Against Recurrent Clostridioides difficile Infection: Efficacy and Side Effects: Two Hospitals Experience. ID Week; 2019; Washington.

253. Johnson. S, D. P, Brown S, editors. Effectiveness of Oral Vancomycin for Prevention of Healthcare Facility-Onset Clostridioides difficile Infection in High-Risk Patients. ID Week; 2019; Washington. 